\title{
Design and Power Dissipation Consideration of PFAL CMOS v/s Conventional CMOS based 2:1 Multiplexer and Full Adder
}

\section{Manvinder Sharma}

Chandigarh Group of Colleges

Digvijay Pandey ( $\square$ digit11011989@gmail.com )

DTE https://orcid.org/0000-0003-0353-174X

\section{Pankaj Palta}

Chandigarh Group of Colleges

\section{Binay Kumar Pandey}

Govind Ballabh Pant University of Agriculture and Technology: Govind Ballabh Pant University of Agriculture \& Technology

\section{Research Article}

Keywords: Low Power Design, Adiabatic, PFAL, Multiplexer, Adder

Posted Date: April 29th, 2021

DOl: https://doi.org/10.21203/rs.3.rs-427022/v1

License: (9) This work is licensed under a Creative Commons Attribution 4.0 International License. Read Full License 


\title{
Design and Power Dissipation Consideration of PFAL CMOS v/s Conventional CMOS based 2:1 Multiplexer and Full Adder
}

\author{
Manvinder Sharma ${ }^{1}$, Digvijay Pandey ${ }^{2}$, Pankaj Palta ${ }^{3}$ and Binay Kumar Pandey ${ }^{4}$ \\ ${ }^{1,3}$ Department of ECE, Chandigarh Group of Colleges, Landran, Punjab India \\ ${ }^{2}$ Department of Technical Education, IET, Dr. A.P.J. Abdul Kalam Technical University, Uttar \\ Pradesh,India \\ ${ }^{4}$ Departmentt of IT,College of Technology, GovindBallabh Pant University of Agriculture and Technology, \\ U.K, India \\ e-mail:digit11011989@gmail.com,manvinder.sharma@gmail.com
}

\begin{abstract}
Increasing transistor switching time and rising count of transistors integrated over a chip area has given a high pace in computing systems by several orders of magnitude. With the integration of circuits, number of gates and transistors are increasing per chip area. CMOS Logic family is preferred due to its performance and impeccable noise margins over other families. However with integration in every digital circuit, the energy due to switching of gate doesn't decrease at same rate as gates are increased per chip area. Due to this, power dissipation becomes significant and also reduction of heat becomes more complicated and expensive. In CMOS based circuits dynamic power requirement is becoming major concern in digital circuits. In this paper, the work is focused on reducing the power dissipation in circuits which is increasing with down scaling of circuits. The work is done on 2:1 multiplexer and full adder circuit. Adiabatic logic with positive feedback (PFAL) is applied to redesign the circuit with input power taken as sinusoidal source of $3.3 \mathrm{~V}$ and analysis is done for power dissipation between conventional CMOS and PFAL based CMOS circuits. In comparison with the conventional CMOS 2:1 multiplexer circuit, the designed PFAL CMOS 2:1 multiplexer circuit has less power dissipation as 80.871 picoWatts while conventional CMOS circuit has 6.9090 nanoWatts with the same behavior of circuit. Also for full adder conventional CMOS circuit have 48.0452 picoWatts while PFAL based full adder has 3.9089 picoWatts.
\end{abstract}

Keywords-Low Power Design; Adiabatic; PFAL; Multiplexer; Adder

\section{INTRODUCTION}

For high speed performance in computingand other applications which involve processing, computing and analysis of any signal, digital CMOS circuits have been used mostly. Several pros over other families which include perfect logic levels, impeccable noise margins, better performance and almost negligible static power dissipation CMOS logic family is preferred. As we need faster processing of signals, the demand of these circuits is high and is going to increase in near future. Faster speed in computing is achieved with the increase in number of transistors integrated over a chip. However such improvement in performance is accompanied with increase in energy dissipation and power dissipation [1]. The disadvantage of higher energy and power dissipation is that the circuits require more expensive packaging and expansive cooling technology which decreases reliability also increases cost. As the level of clock frequency and on-chip integration will continue to grow as per the demands of faster computing, the energy and power dissipation of these high performance circuits is a perilous design issue [2]. To achieve Tera Instructions per seconds (TIPS) high end 
microprocessor employ billions of transistor on chip at clock rates over $30 \mathrm{GHz}$, with this rate of speed power dissipation of circuit is projected to extend to thousands of watts. Such power dissipation density introduces reliability concerns like hot carrier, thermal stress and electromigration which degrade the performance of circuits. Also for the requirement of low power chips or low battery consuming chips the higher power dissipation circuits will consume more power from the battery [3-5]. For the portable digital systems that run on batteries like notepads, laptops, tablets etc the prime concern is low power consumption and this also increases the battery longevity.

The power consumed by any device is the energy consumed per unit time.

$$
E=\int_{0}^{T_{o p}} P(t) d t
$$

For a given operation the energy $(\mathrm{E})$ required is integral of power $(\mathrm{P})$ consumed over operation time $\left(\mathrm{T}_{\mathrm{op}}\right)$

The power of digital CMOS circuit is given by

$$
\mathrm{P}=\mathrm{C} . \mathrm{V}_{\mathrm{DD}} . \mathrm{V}_{\mathrm{s} .} \mathrm{f}
$$

Where $\mathrm{V}_{\mathrm{DD}}$ is supply voltage, $\mathrm{f}$ is clock frequency, $\mathrm{C}$ is capacitance being recharged and $\mathrm{V}_{\mathrm{s}}$ is voltage swing of signal.

The energy consumption can be given by

$$
\mathrm{E}=\mathrm{n} . \mathrm{C} . \mathrm{V}_{\mathrm{DD}} \cdot \mathrm{V}_{\mathrm{S}}
$$

In this equation energy consumption is independent of clock frequency. As the battery life is determined by energy consumption it is imperative to reduce energy as compared with power. However power is critical for heat dissipation considerations. So optimization of both factors energy as well as power is required [6].

In CMOS circuit, power dissipation is composed of static and dynamic power dissipation. Static power dissipation is power dissipated in steady state and is given by

$$
\mathrm{P}_{\mathrm{stst}}=\mathrm{I}_{\mathrm{stat}} . \mathrm{V}_{\mathrm{DD}}
$$

Where $\mathrm{I}_{\text {stat }}$ is current when circuit is in steady state or in the absence of switching activity. However theroticlly, in static state there is no direct path from $\mathrm{V}_{\mathrm{DD}}$ to ground (pMOS) and no transistor is on state (nMOS) there is no static power dissipation [7]. But in practice Metal-Oxide-Semiconductor (MOS) is not a perfect or impeccable switch due to this there is always a substrate injection current and leakage current which introduces static power dissipation [8-10]. For 5 Volts of $V_{D D}$, substrate injection current for a nMOS device $(\mathrm{W} / \mathrm{L}=10 / 0.5)$ is in order to $1-100 \mu \mathrm{A}[11]$.

Another subcategory of static power dissipation is ratioed logic. As CMOS family is ratioed family pull up of pMOS is in always on state which also acts as load for pull down nMOS network. In low state, when gate output is low there is direct path for current from $\mathrm{V}_{\mathrm{DD}}$ to ground. In this state static current flows. So in CMOS family static power consumption is considerable. Figure 1 shows the CMOS Inverter operation. 


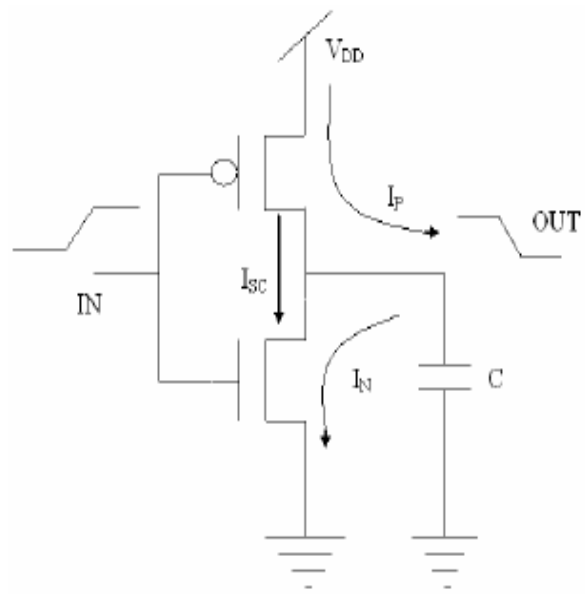

Figure 1. CMOS Inverter for power analysis

Dynamic power dissipation is introduced in the circuit while switching activity, or in transition state. During the transient activity, at a point which is $\mathrm{V}_{\mathrm{tn}}$ (nMOS threshold point) and $\mathrm{V}_{\mathrm{DD}}-\mathrm{V}_{\mathrm{tp}}(\mathrm{pMOS}$ threshold point) both pMOS and nMOS are turned on. A short circuit exists in this duration and current has path from $V_{D D}$ to ground. With the cautious designing of edges of transition this effect can be minimized to ten to fifteen percent of power of total. The other factor affecting dynamic dissipation is due to charging of parasitic capacitance and discharging of parasitic capacitance within the circuit [12]. In figure 1, the parasitic capacitance is shown as a output as a capacitor. Considering one full cycle of operation from $\mathrm{V}_{\mathrm{DD}}$ to GND and from GND to $\mathrm{V}_{\mathrm{DD}}$, the process of charging the capacitor draws energy from the power supply which is equal to $\mathrm{C}$. $\left(\mathrm{V}_{\mathrm{DD}}\right)^{2}$. Half power is stored in capacitor while half is dissipated in pMOS, during operation ground to $\mathrm{V}_{\mathrm{DD}}$, the capacitance is discharged and energy is dissipated in nMOS. For each time the capacitance switches, energy equals to $\mathrm{C}$. $\left(\mathrm{V}_{\mathrm{DD}}\right)^{2}$ is dissipated. The dynamic dissipation can be formulated as

$$
\mathrm{P}_{\mathrm{dyn}}=\alpha \mathrm{CV}_{\mathrm{DD}}^{2} \mathrm{f}
$$

Where, $\alpha$ is expected number of 0 to 1 transitions per data cycle, $f$ is clock frequency.

\section{PFAL MODELING DESIGN}

The dissipation takes most of power dissipation almost $90 \%$. To reduce this dissipation, designers can decrease node capacitance, minimize switching events, reduce voltage swing or also can smear grouping of these. But in all these methods before power dissipation, energy which is drawn from power supply is used once. However, if we introduce recycling of energy drawn from power supply, the energy efficiency of logic circuits can be achieved [10]. The possibility of reusing energy drawn from the supply and reducing the energy dissipation during switching is offered by a class of circuits known as Adiabatic logic circuits. In this logic, the energies stored in capacitance are reused instead of being dissipated as heat. This is also known and energy recovery CMOS. By only switching the transistors under certain conditions and slowing switching process one can achieve very low power dissipation in the circuit [11]. 


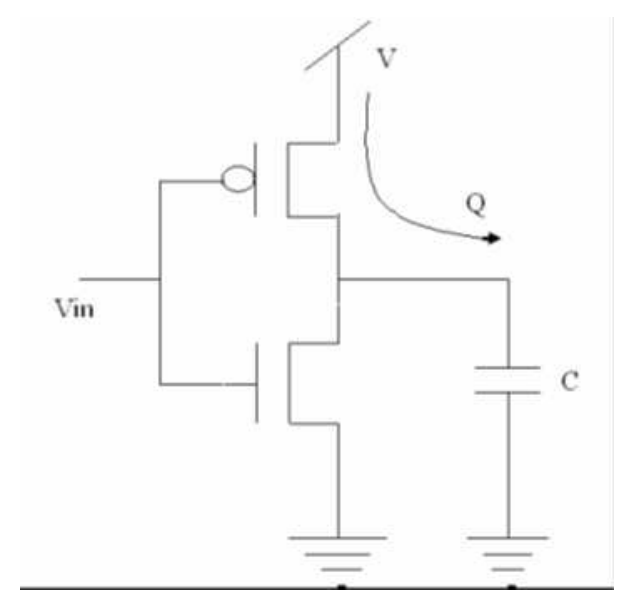

Figure 2. Adiabatic CMOS as Inverter

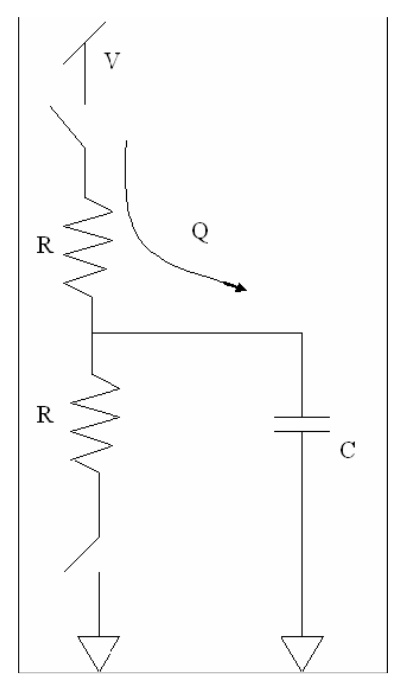

Figure 3. Equivalent resistive circuit of Inverter

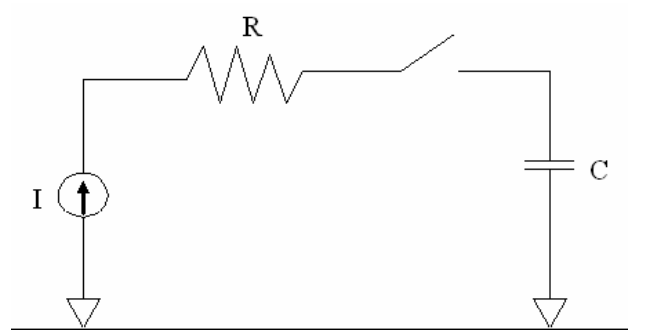

Figure 4. Adiabatic switching

Figure 2,3,4 shows adiabatic switching process, Instead of constant voltage source [14], the capacitance is charged by constant current source, R shows resistance of pMOS,

A constant charging current corresponds to linear voltage ramp.

Initially, let us assume capacitance voltage $\mathrm{V}_{\mathrm{C}}=0$

IR be the voltage across switch

$\mathrm{P}(\mathrm{t})$ in the switch $=\mathrm{I}^{2} \mathrm{R}$

Energy during charge $=\left(\mathrm{I}^{2} \mathrm{R}\right) \mathrm{T}$

$$
\therefore I=\frac{C V}{T} \rightarrow T=\frac{C V}{I}
$$




$$
\begin{aligned}
& E=\left(I^{2} R\right) T=\left(\frac{C V}{T}\right)^{2} R T=\frac{C^{2} V^{2} R}{T} \\
& E=E_{\text {diss }}=\left(\frac{R C}{T}\right) C V^{2}=\left(\frac{2 R C}{T}\right)\left(\frac{1}{2} C V^{2}\right)
\end{aligned}
$$

E is energy dissipated, Q is charge transfer to load, C is load capacitance, R is Resistance of MOS Switch, $\mathrm{V}$ is final value of voltage and $\mathrm{T}$ is time spent at load.

From equation 9, if the charging time $(\mathrm{T})$ is greater than $2 \mathrm{RC}$, the energy dissipation can be made small by increasing charging time. Opposed to conventional CMOS, the dissipated energy is proportional to R instead of capacitance and voltage swing. Reducing on resistance of pMOS will reduce energy dissipation.

To reuse the power a different type of power supply is used in the adiabatic logic. The source needed for adiabatic operation is usually a sinusoidal or a trapezoidal source. This supply can also act as clock for circuit. Figure 5 shows trapezoidal power supply. The four phases idle, evaluate, hold and recovery shows the process. Idle is equal to 0 and hold is equal to 1 . While in evaluate phase, depending upon input the load capacitance charges up or does not and in recovery phase the charge held on capacitance is recovered.

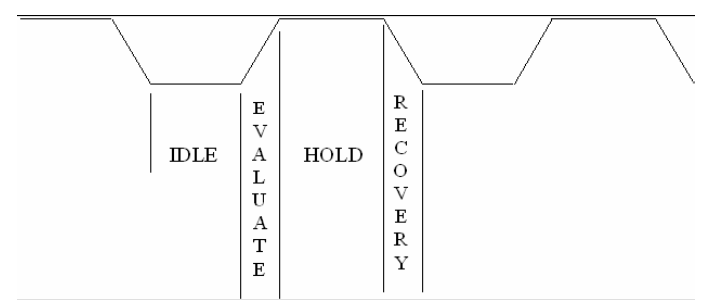

Figure 5. Different phases in adiabatic power supply.

Positive feedback adiabatic logic (PFAL) is the category under adiabatic logic family. As compared to other families like ECRL, 2N-2N2P, CAL this PFAL has lowest energy consumption [15]. It is robust against technological parameter variations. The core of PFAL is adiabatic amplifier, latch made by two nMOS and two pMOS. The two n-trees reliaze logic functions as well as it can generate both positive and negative outputs which can be used as per requirement. Figure 6 shows general schematic of PFAL gate [16-17]. Two latches M1 and M2 and M3 and M4 formed by pMOS andnMOS.

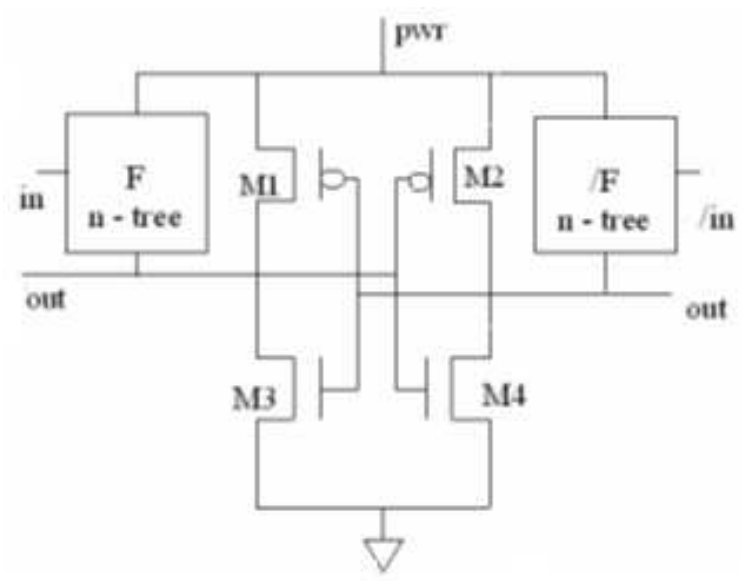

Figure 6.General schematic of PFAL gate.

In mentor graphic design architect IC conventional CMOS based 2:1 multiplexer is modeled and analyzed for power dissipation which is shown in figure 7 and figure 8 shows conventional CMOS based full adder which is modeled and analyzed. 


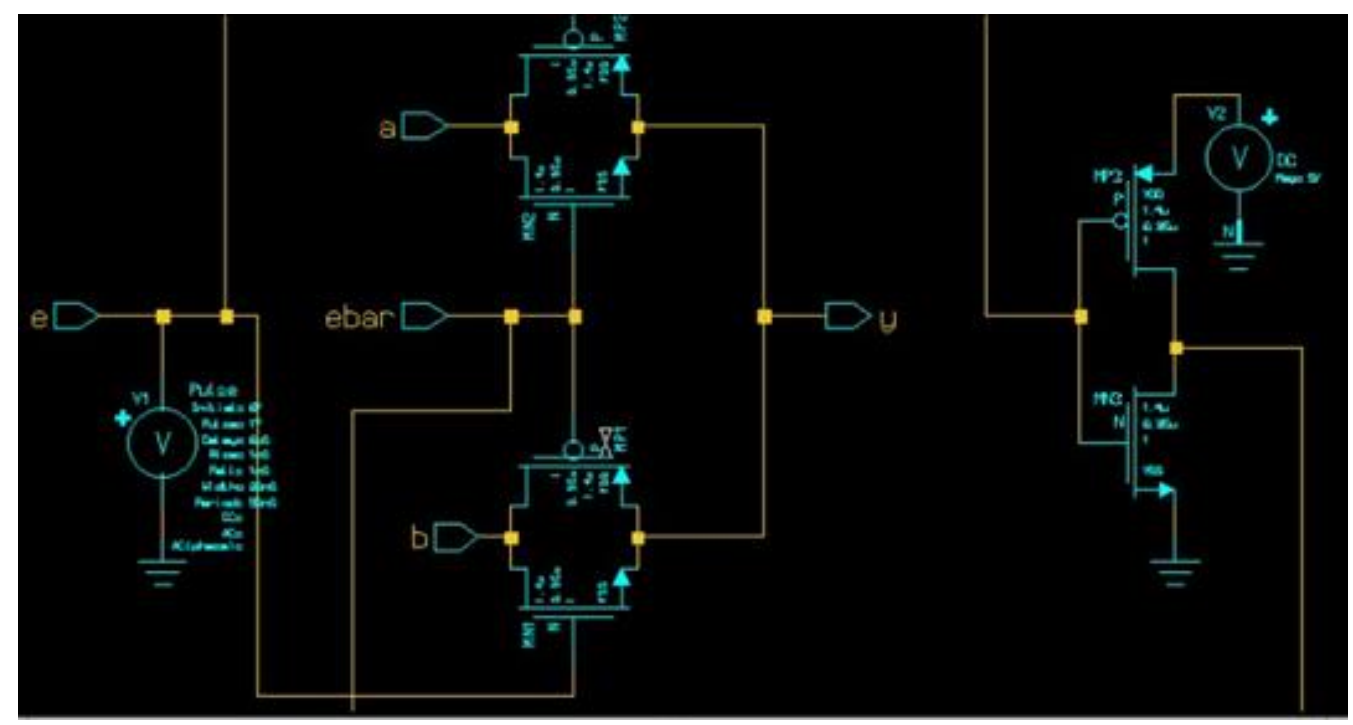

Figure 7. Conventional CMOS based 2:1 Multiplexer

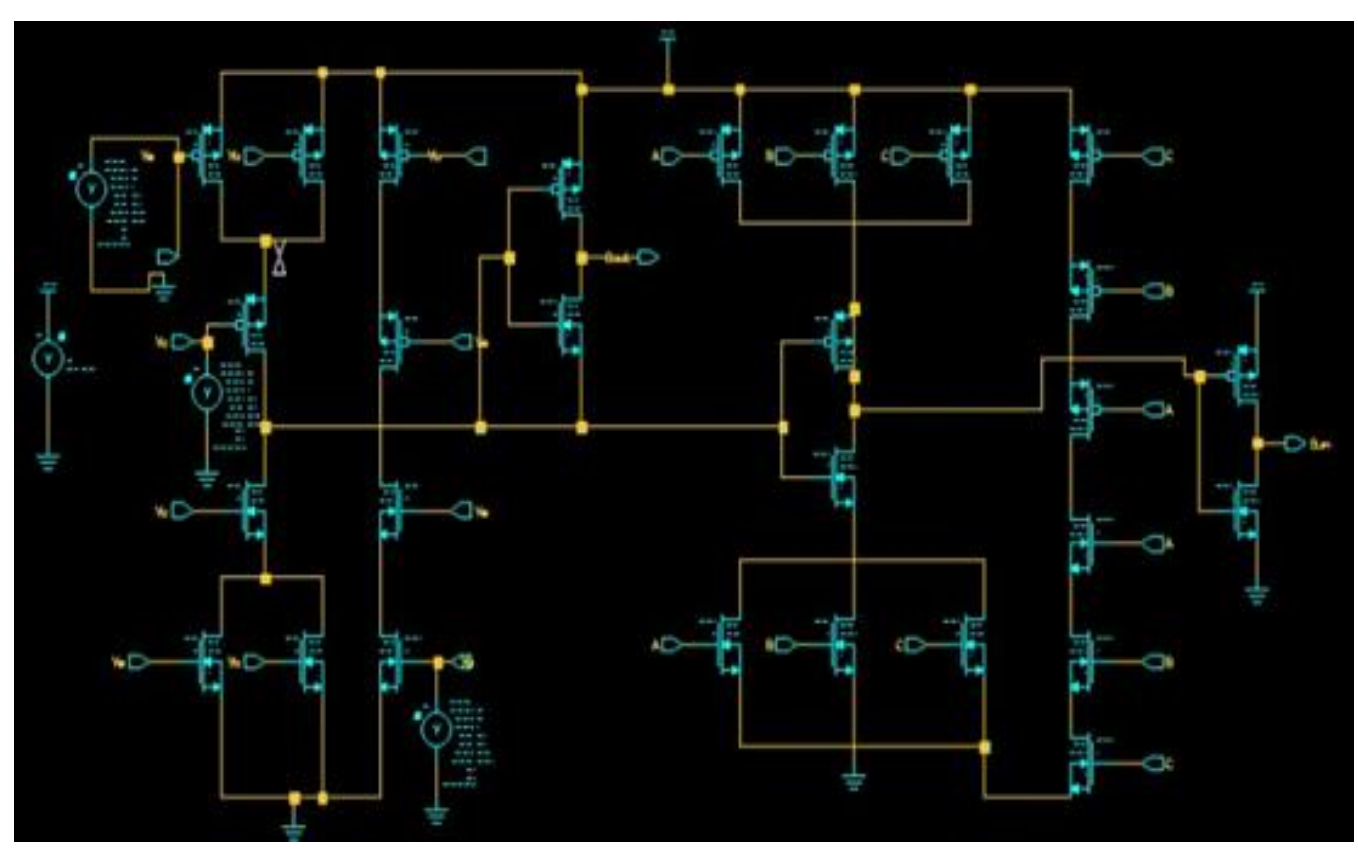

Figure 8. Conventional CMOS based Full Adder

Using the discussed methodology, PFAL based 2:1 multiplexer and full adder is designed and modeled in mentor graphic design architect IC and is shown in figure 9 and figure 10 respectively. The designs are simulated in ELDONET tool. 


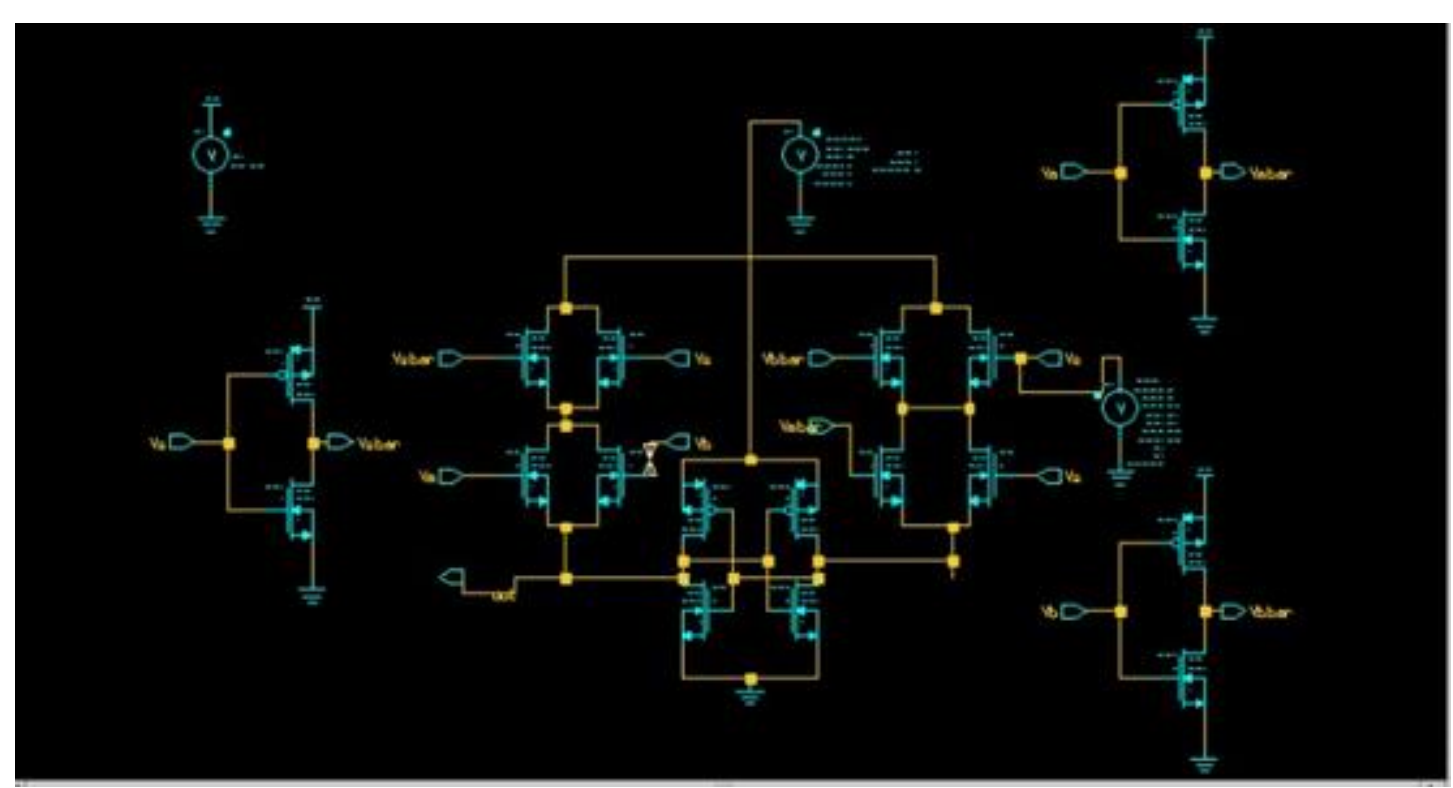

Figure 9. PFAL CMOS 2:1 Multiplexer

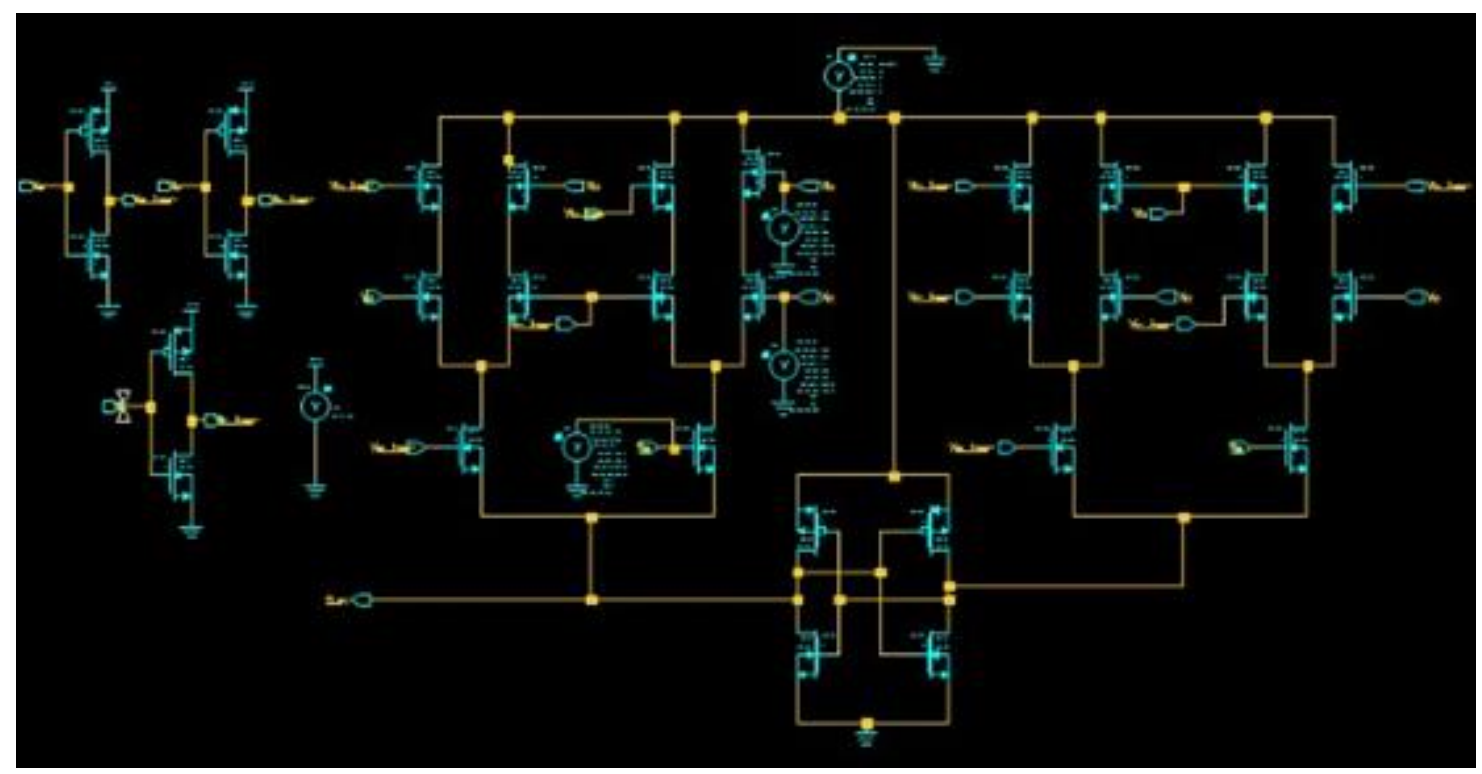

Figure 10. PFAL CMOS based Full Adder

\section{RESUlTS AND DISCUSSIONS}

First, The design structure includes PFAL based CMOS which is modeled in Mentor Graphic tool named Design Architect using standard TSMC $0.35 \mu \mathrm{m}$ CMOS technology. At an operating temperature of $27^{\circ} \mathrm{C}$ input voltage 3.3 V supply is provided. The ELDONET tool is used to simulate and check the results for power dissipation for conventional CMOS and PFAL designed circuits.

For the conventional circuit $\mathrm{V}_{\mathrm{DD}}$ is taken as constant DC source with a value of $\mathrm{V}_{\mathrm{DD}}$ equals to $3.3 \mathrm{~V}$. The circuits are shown in figure 7 and figure 8. For PFAL circuit the reconstruction is done from conventional circuit using same method to make PFAL circuits. The circuits are modeled and shown in figure 9 and figure 10. The source for the circuit is taken as SIN source and sine ac wave is provided as power supply of 3.3V.

The design is simulated in ELDONET environment. The figure 11 and figure 12 shows results after simulation of conventional CMOS 2:1 Multiplexer. The calculated power dissipation after simulation of conventional 2:1 multiplexer is 6.9090 nano Watts. 


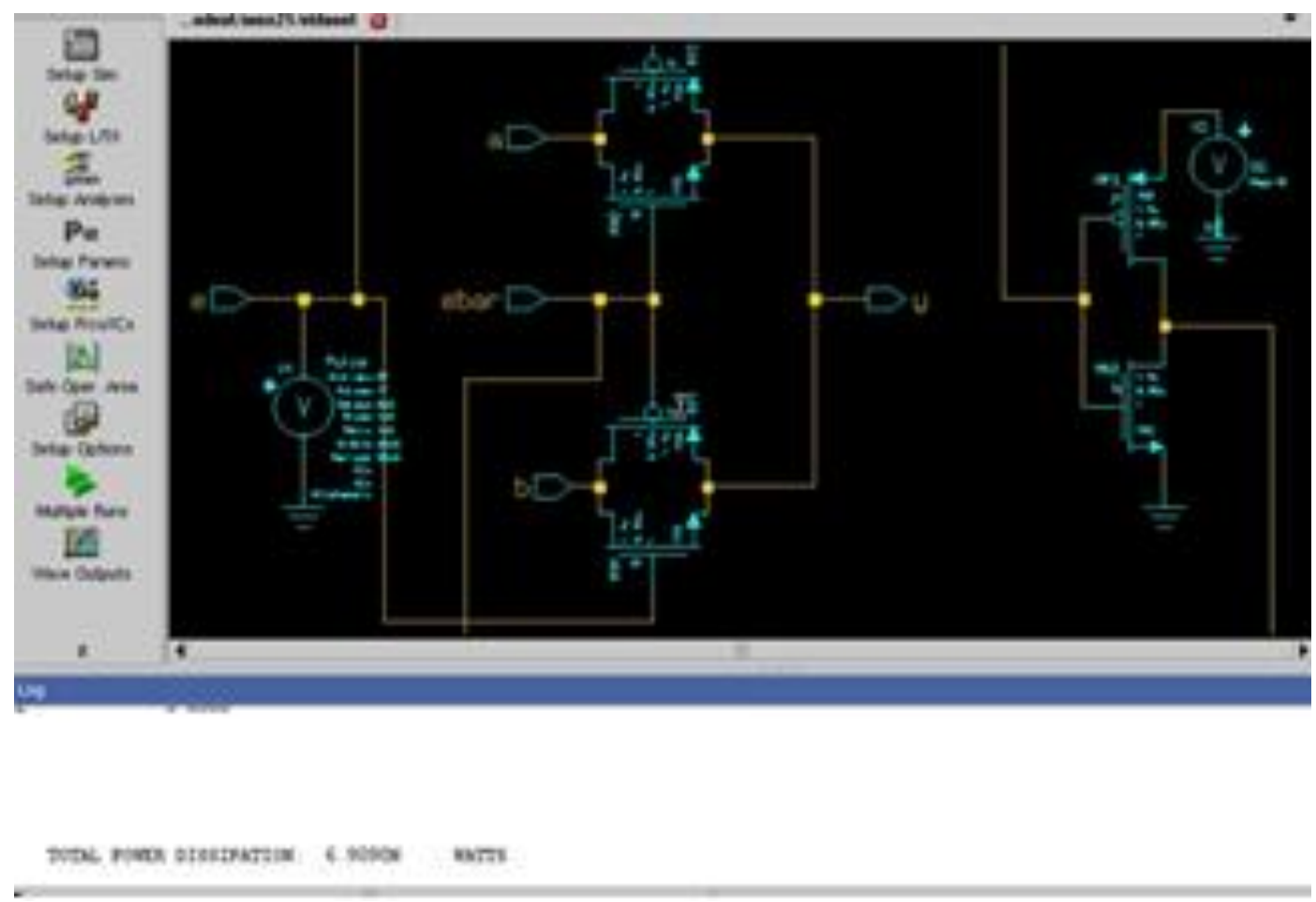

Figure 11. Calculated power dissipation of Conventional CMOS based 2:1 Multiplexer

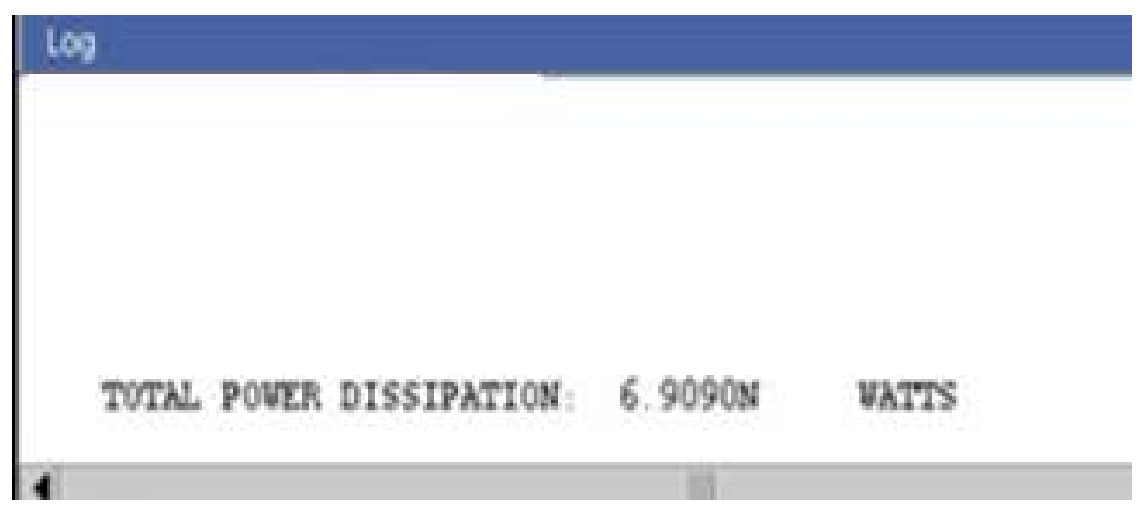

Figure 12. Log window of power dissipation of Conventional CMOS based 2:1 Multiplexer

PFAL 2:1 multiplexer is simulated and results as power dissipation is shown in figure 13 and figure 14. The calculated power dissipation in this circuit is 80.8716 pico Watts. It can be observed that the power dissipation is reduced with high rate with the same working of circuit. Figure 15 shows the comparison of power dissipation for 2:1Multiplexer. 


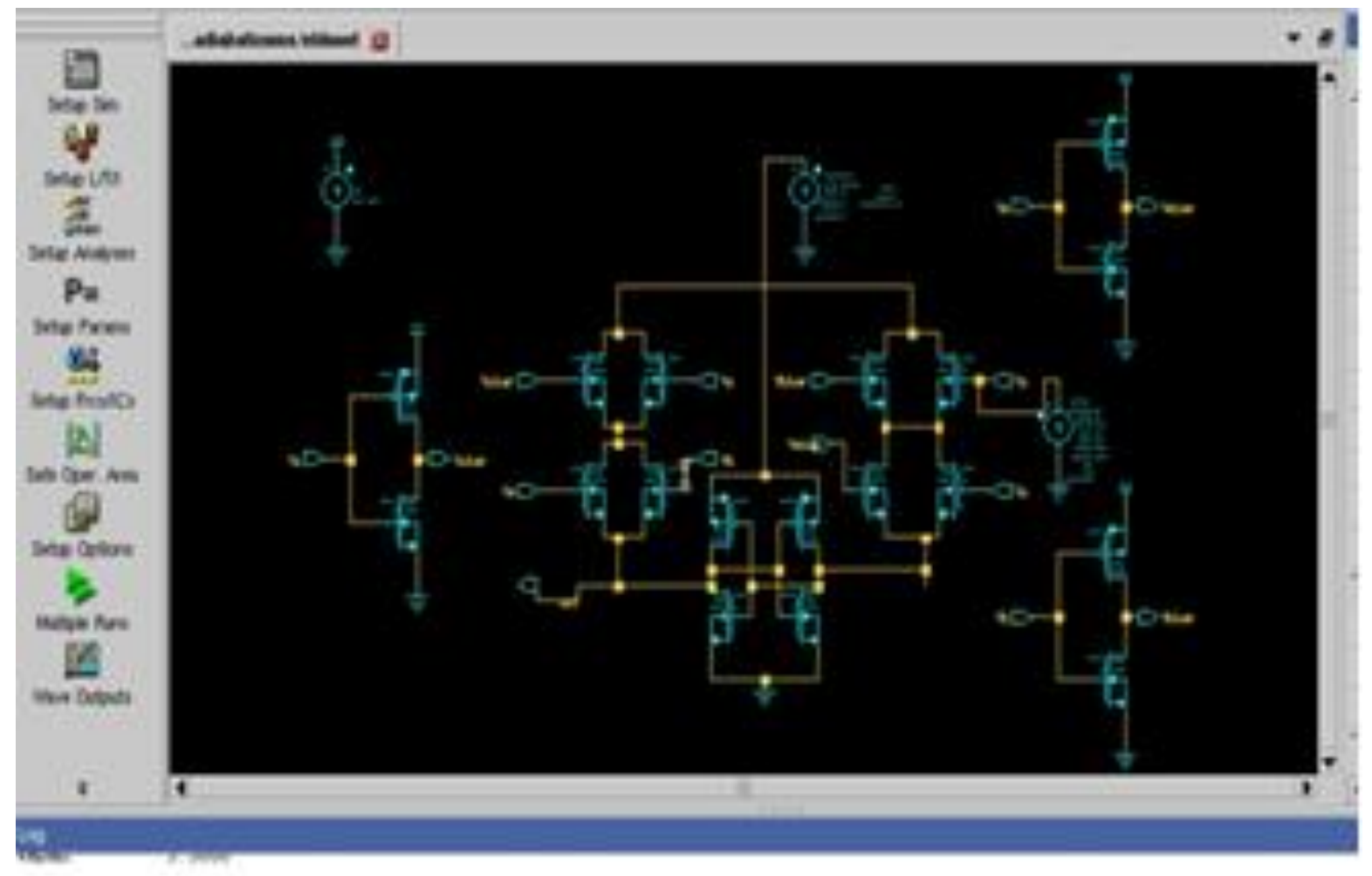

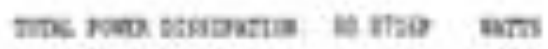

Figure 13. Calculated power dissipation of PFAL CMOS based 2:1 Multiplexer

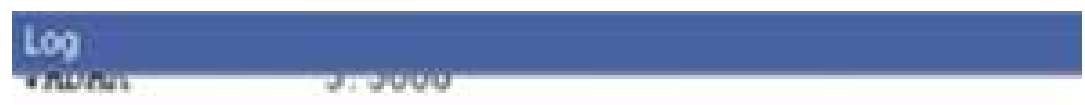

TOTAL POVER DISSIPATION: $80.8716 \mathrm{P}$ VATS

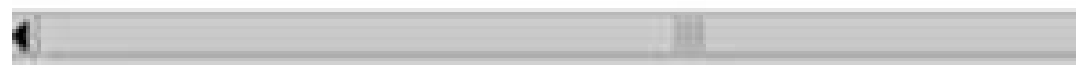

Figure 14. Log window of power dissipation for PFAL based 2:1 Multiplexer 


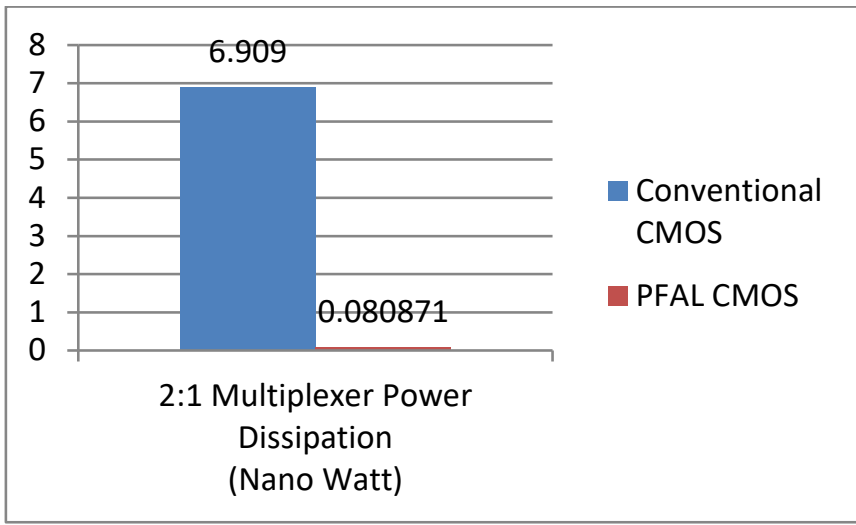

Figure 15. Graphical representation of reduction in power dissipation of 2:1 Multiplexer

The figure 16 and figure 17 shows results after simulation of conventional CMOS full adder. The calculated power dissipation after simulation is 48.0452 picoWatts.

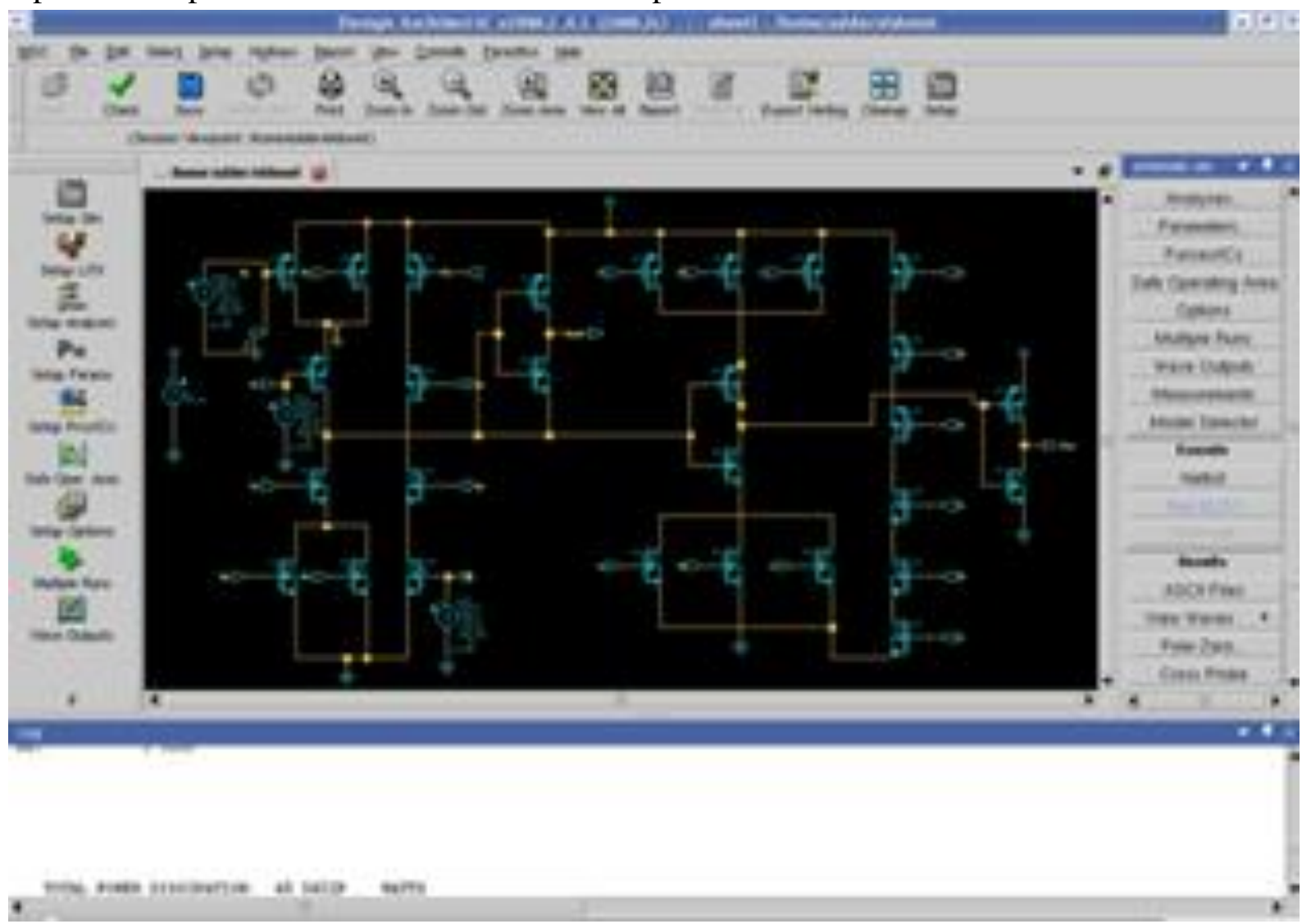

Figure 16. Calculated power dissipation of conventional CMOS based Full Adder

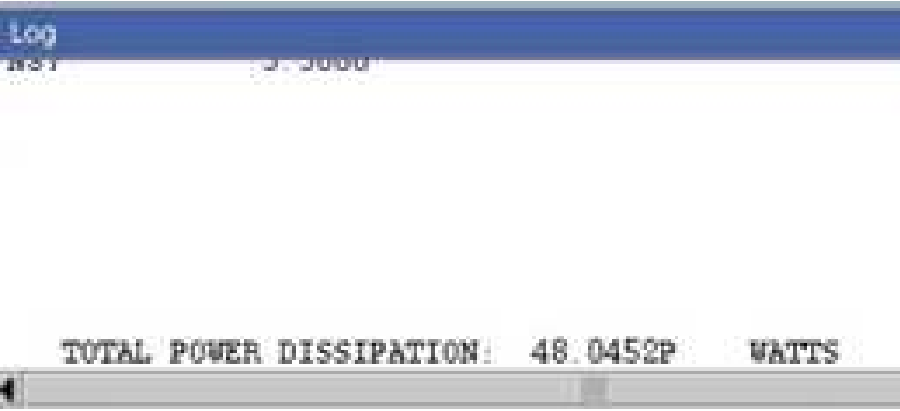

Figure 17. Log window of power dissipation of conventional CMOS based Full Adder 


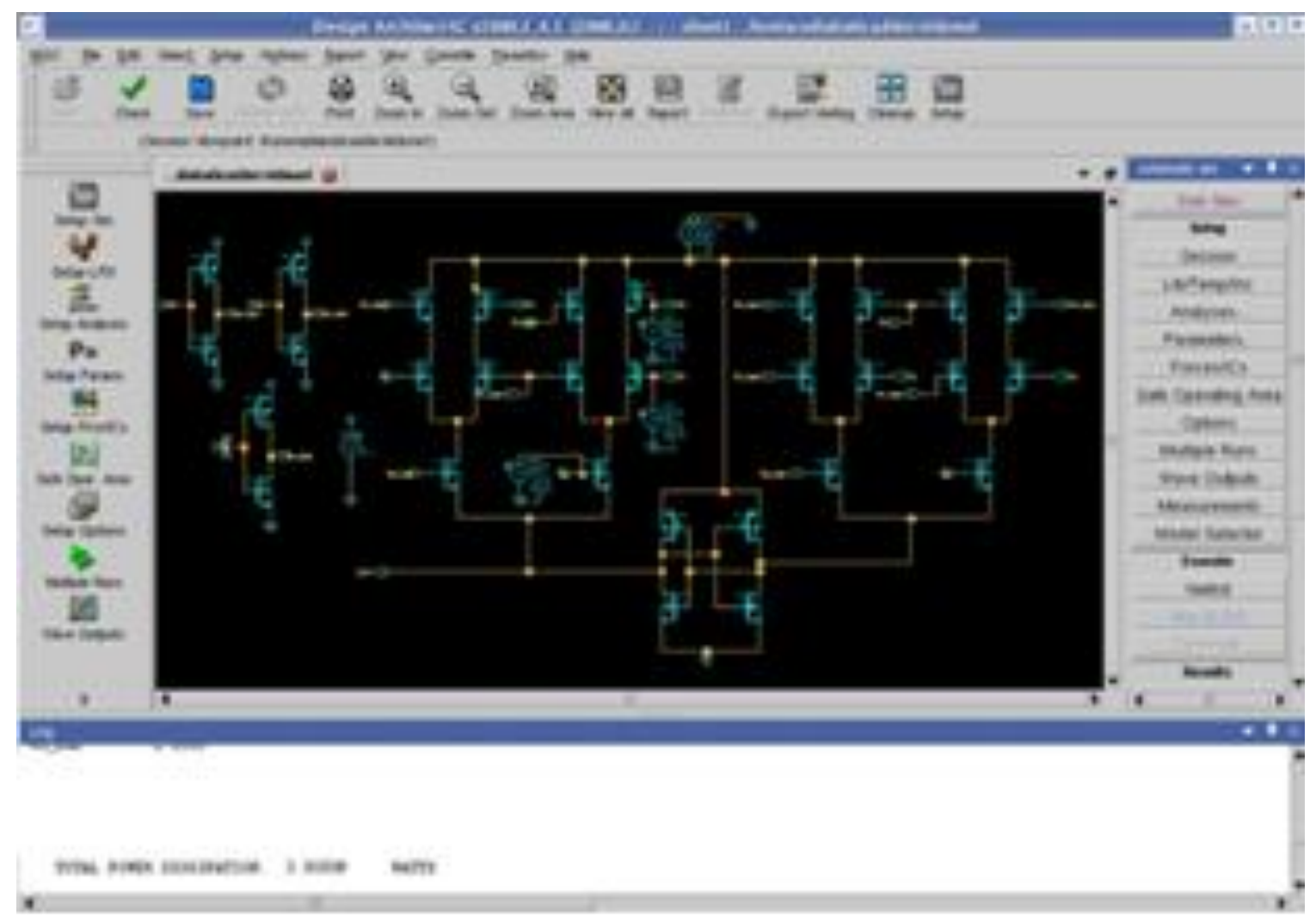

Figure 18. Calculated power dissipation of PFAL based Full Adder

PFAL CMOS based full adder is simulated and results as power dissipation is shown in figure 18 and figure 19. The calculated power dissipation in this circuit is 3.9089 picoWatts. It can be observed that the power dissipation is reduced with the same working of circuit. Figure 20 shows the comparison of power dissipation for both full adder circuit.

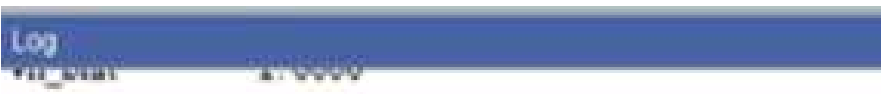

TUTAL POVER DISSIPATION: $3.9089 \mathrm{P}$ VATS

Figure 19. Log window of power dissipation for PFAL based Full Adder.

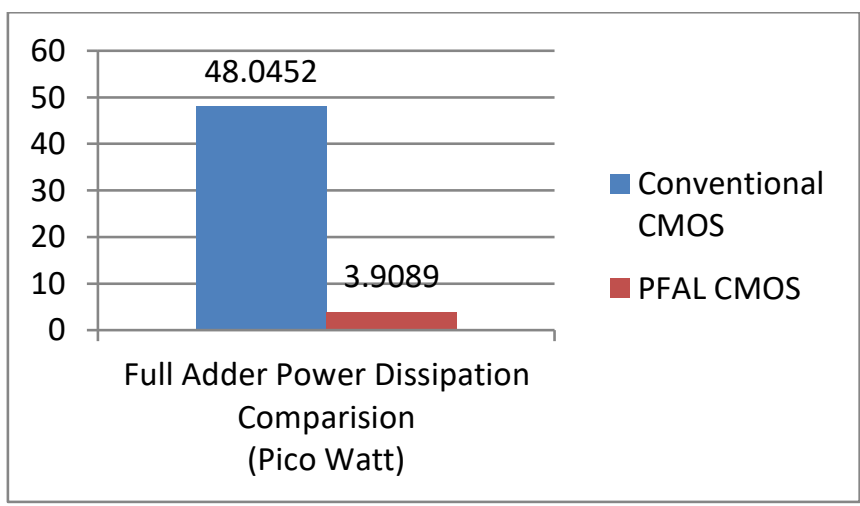

Figure 20. Graphical representation of reduction in power dissipation of Full Adder Circuit 
Table 1 shows the different circuit modeled and simulated in eldonet environment and their power dissipation.

Table 1. Power dissipation of Conventional CMOS v/s PFAL CMOS

\begin{tabular}{|l|c|}
\hline Circuit & $\begin{array}{c}\text { Power Dissipation } \\
\text { (Watts) }\end{array}$ \\
\hline Conventional CMOS 2:1 Multiplexer & 6.9090 Nano \\
\hline PFAL CMOS 2:1 Multiplexer & 80.871 Pico \\
\hline Conventional CMOS Full Adder & 48.0452 Pico \\
\hline PFAL CMOS Full Adder & 3.9089 Pico \\
\hline
\end{tabular}

After the simulation of all circuits (convention CMOS 2:1 multiplexer, Conventional CMOS full adder, PFAL CMOS 2:1 multiplexer and PFAL full adder) it can be clearly seen that the power dissipation of the circuit using PFAL is reduced to a much lower value.. However the circuit for PFAL has increased the number of gates required to perform any logic but it is also providing both original and its complement outputs. This can eliminate the requirement of other circuit where complement of output is also required for many applications

\section{Conclusion}

While rate of integration of transistor per chip area is increasing day by day. This leads to power dissipation and expansive heat cooling methods. The power dissipation directly affects the device performance in reliability terms and performance of circuit. The focus is on reducing the power dissipation. In this paper, another approach for reducing and reusing the power and energy dissipation is discussed. Using PFAL method, 2:1 multiplexer circuit power dissipation is reduced to picoWatts from nanoWatts of conventional CMOS circuit. For full adder the power dissipation is also reduced for PFAL circuitry. This shows the effectiveness of PFAL and adiabatic logic family. The circuits can be made with this approach to reduce the power dissipation. With the less power dissipation and consumption the hand held devices like laptop, mobiles, notepads etc will have longevity of battery. Also the cost of expensive heat cooling will be reduced

\section{Acknowledgements}

The authors would like to express gratitude to Department of Technical Education and Chandigarh Group of Colleges, Landran, Punjab India. The authors would also like to thank to Vice Chancellor, Dr. A.P.J. Abdul Kalam Technical University, and Uttar Pradesh, India

\section{Code Availability}

The relevant code with the manuscript is also available and would be available, if will be asked to do so later.

Funding statement: The author(s) received no financial support for the research, authorship, and/or publication of this article. 
The data samples have been taken using PFAL.

\section{Contributions}

All authors approve the final manuscript.

\section{Ethics declarations}

\section{Ethics Approval}

Not Applicable (as the results of studies does not involve any human or animal).

\section{Consent to Participate}

Not Applicable (as the results of studies does not involve any human or animal).

\section{Consent for Publication}

Not Applicable (as the results of studies does not involve any human or animal).

Conflict of Interests/ Competing Interests

The authors declare that they have 'no known conflict of interests or personal relationships' that could have appeared to influence the work reported in this paper.

\section{REFERENCES}

[1] Samaali, Hatem, Y. Perrin, A. Galisultanov, H. Fanet, Gaël Pillonnet, and Philippe Basset. "MEMS four-terminal variable capacitor for low power capacitive adiabatic logic with high logic state differentiation." Nano Energy 55 (2019): 277-287.

[2] Liu, Jheng-Sin, Michael B. Clavel, and Mantu K. Hudait. "TBAL: Tunnel FET-Based Adiabatic Logic for Energy-Efficient, Ultra-Low Voltage IoT Applications." IEEE Journal of the Electron Devices Society 7 (2019): 210-218.

[3] Raghav, H. S., Bartlett, V. A., \& Kale, I. (2018). Investigating the effectiveness of Without Charge-Sharing Quasi-Adiabatic Logic for energy efficient and secure cryptographic implementations. Microelectronics journal, 76, 8-21.

[4] A. P. CHANDRAKASAN, S. SHENG, AND R. W. BRODERSEN, "Low Power CMOS Digital Design,” IEEE Journal of Solid-state Circuits, Vol. 27, No. 04, pp. 473-484, April 1999.

[5] H. J. M. VEENDRICK, "Short-circuit Dissipation of Static CMOS Circuitry and its Impact on the Design of Buffer Circuits," IEEE JSSC, pp. 468-473, August 1984.

[6] J. M. RABAEY, AND M. PEDRAM, "Low Power Design Methodologies,” Kluwer Academic Publishers, 2002.

[7] BLOTTI AND R. SALETTI, "Ultralow- Power Adiabatic Circuit Semi-Custom Design," IEEE Transactions on VLSI Systems, vol. 12, no. 11, pp. 1248-1253, November 2004.

[8] M. HOROWITZ, T. INDENNAUR, AND R. GONZALEZ, "Low Power Digital Design, "Technical Digest IEEE Symposium Low Power Electronics, San Diego, pp. 08-11, October 1994.

[9] T. SAKURAI AND A. R. NEWTON, "Alpha-Power Law MOSET Model and its Applications to CMOS Inverter Delay and other Formulas," IEEE JSSC, vol. 25, no. 02, pp. 584- 594, October 1990.

[10] A. P. CHANDRAKASAN AND R. W. BRODERSEN, Low-power CMOS digital design, Kluwer Academic, Norwell, Ma, 1995.

[11] J. S. DENKER, "A Review of Adiabatic Computing," Technical Digest IEEE Symposium Low Power Electronics, San Diego, pp. 94-97, October 1994 
[12] B. VOSS AND M. GLESNER, “A Low Power Sinusoidal Clock,” In Proc. of the International Symposium on Circuits and Systems, ISCAS 2001.

[13] W. C. ATHAS, J. G. KOLLER, L. SVENSSON, “An Energy- Efficient CMOS Line Driver using Adiabatic Switching," Fourth Great Lakes symposium on VLSI, California, March 2005

[14] Manvinder Sharma, Harjinder Singh (2018). A Review on Substarte Intergrated Waveguide for mmW. Circulation in Computer Science, ICIC 2018, (June 2018), 137-138

[15] Keote, Minal, and P. T. Karule. "Design and Implementation of Low Power Multiplier Using Proposed Two Phase Clocked Adiabatic Static CMOS Logic Circuit." International Journal of Electrical and Computer Engineering 8, no. 6 (2018): 4959.Y. MOON AND D. K. JEONG, "An Efficient Charge Recovery Logic Circuit," IEEE JSSC, Vol. 31, No. 04, pp. 514-522, April 1996.

[16] A. KAMER, J. S. DENKER, B. FLOWER, et al., "2N2D-order Adiabatic Computation with 2N-2P and 2N2N2P Logic Circuits," In Proc. of the International Symposium on Low Power design, Dana Point, pp. 191-196, 1995.

[17] Anitha, K., and R. Jayachira. "Design and Analysis of CMOS and Adiabatic 1: 16 Multiplexer and 16: 1 Demultiplexer." International Journal of Reconfigurable and Embedded Systems 5, no. 1 (2016). 
Figures

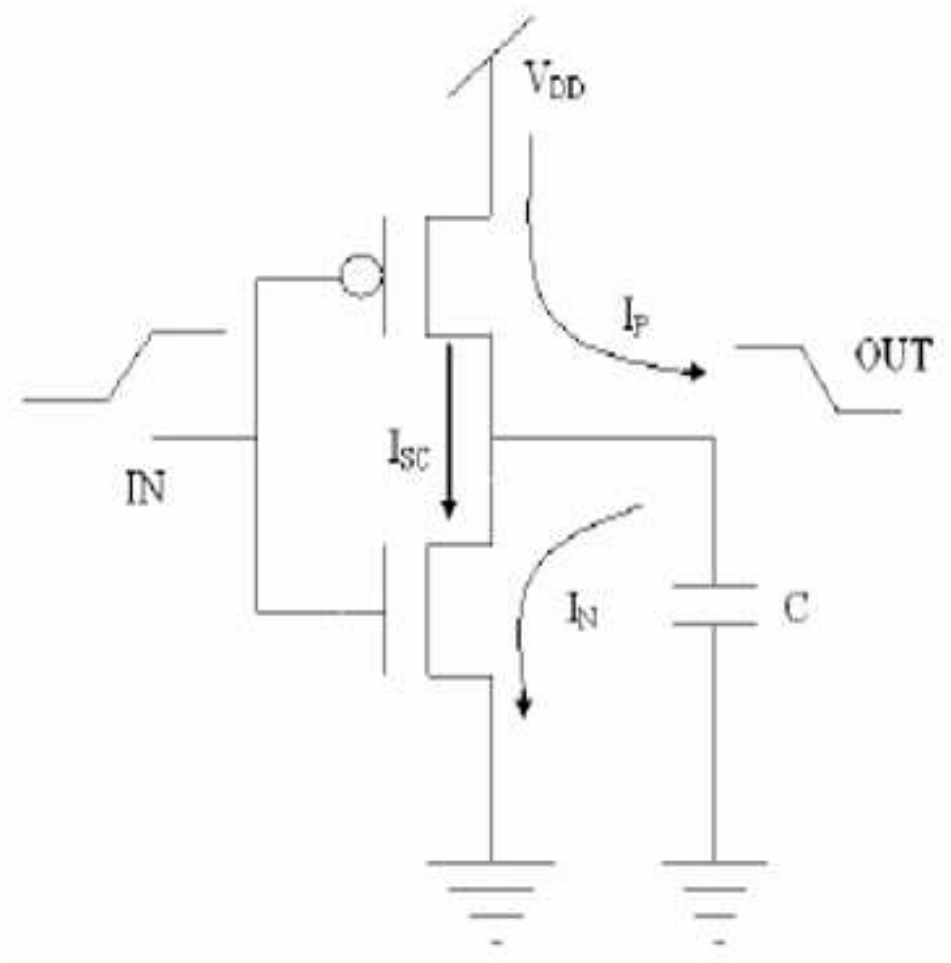

Figure 1

CMOS Inverter for power analysis

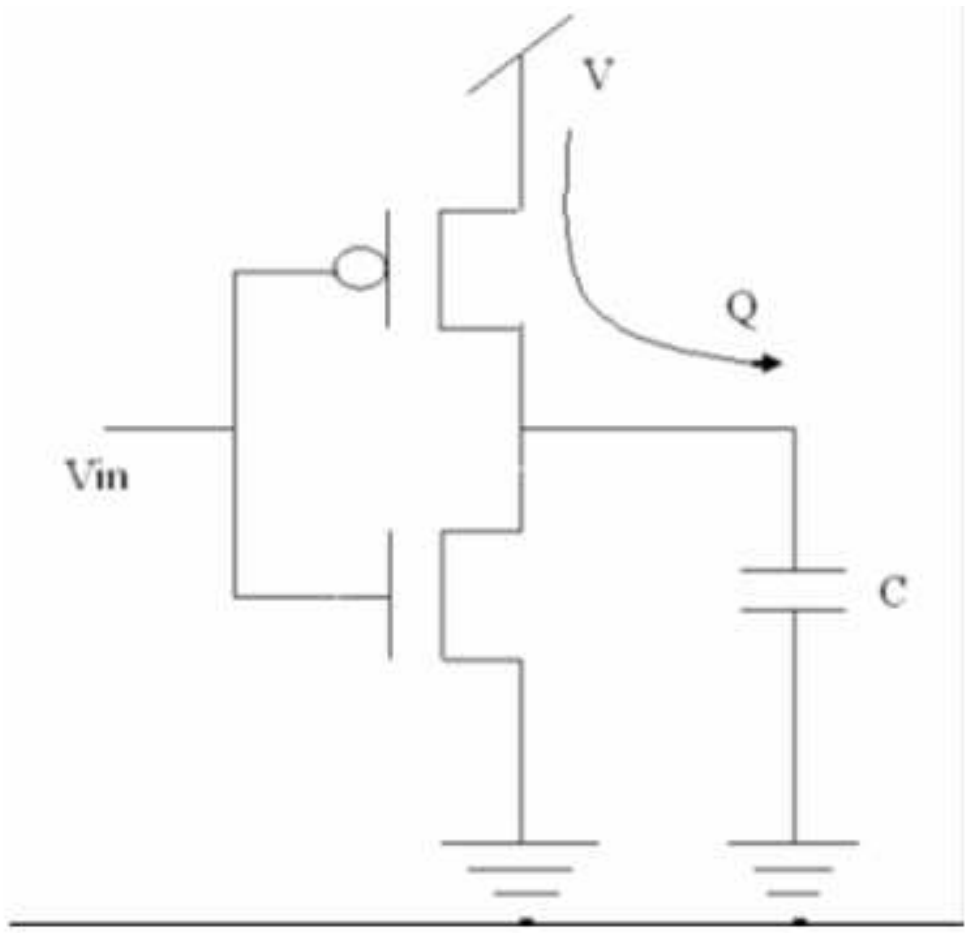

Figure 2 
Adiabatic CMOS as Inverter

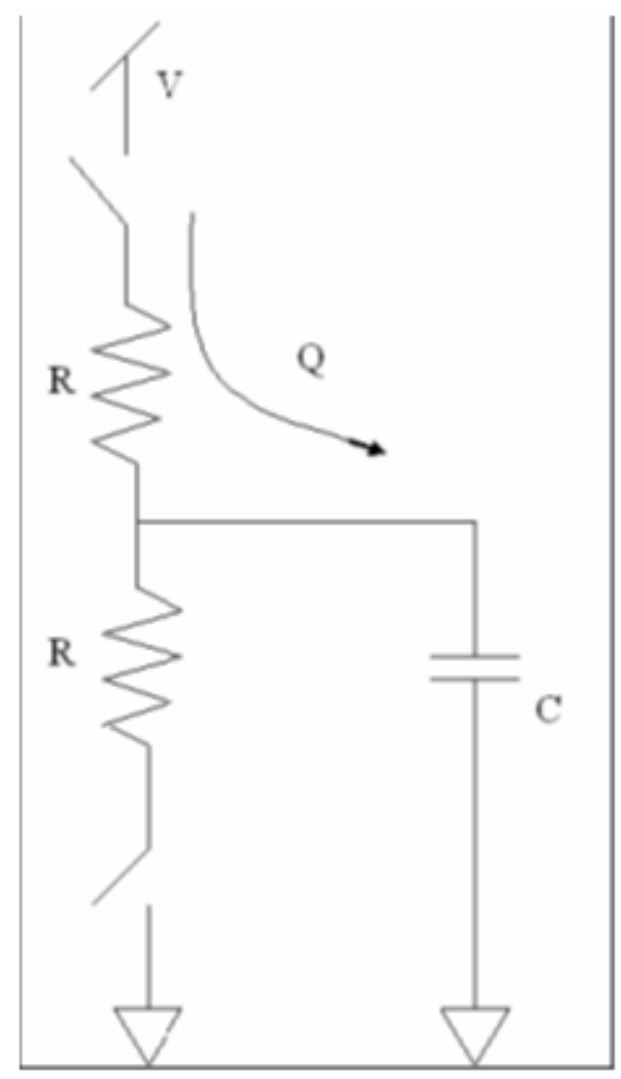

Figure 3

Equivalent resistive circuit of Inverter

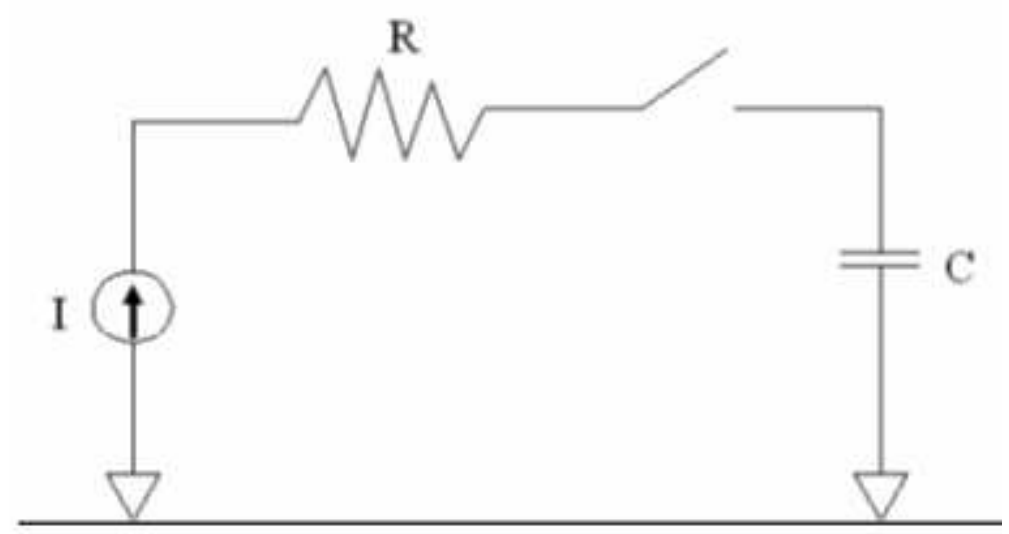

Figure 4

Adiabatic switching 


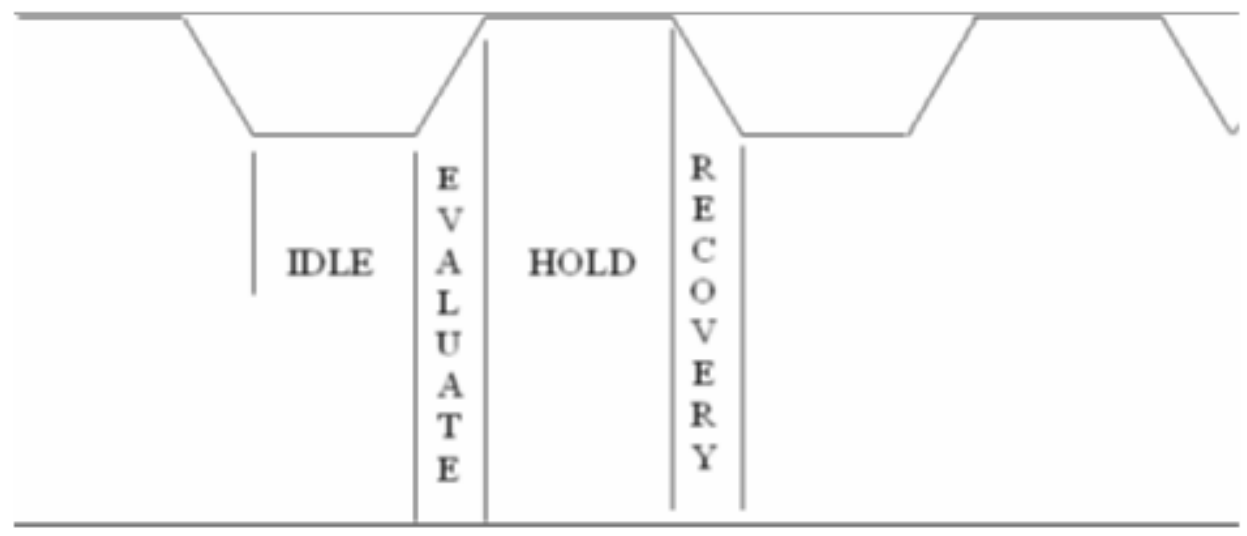

Figure 5

Different phases in adiabatic power supply.

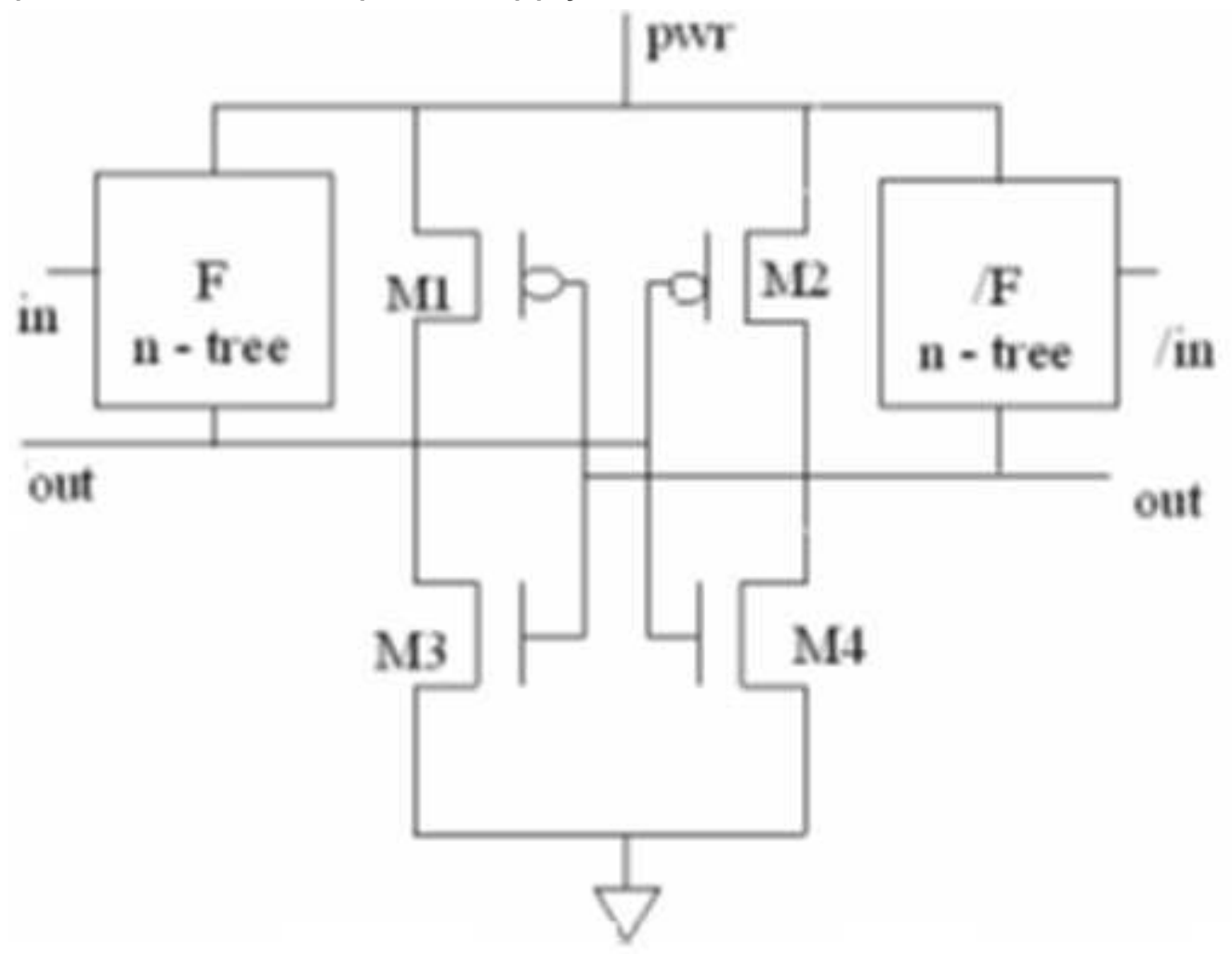

Figure 6

General schematic of PFAL gate. 


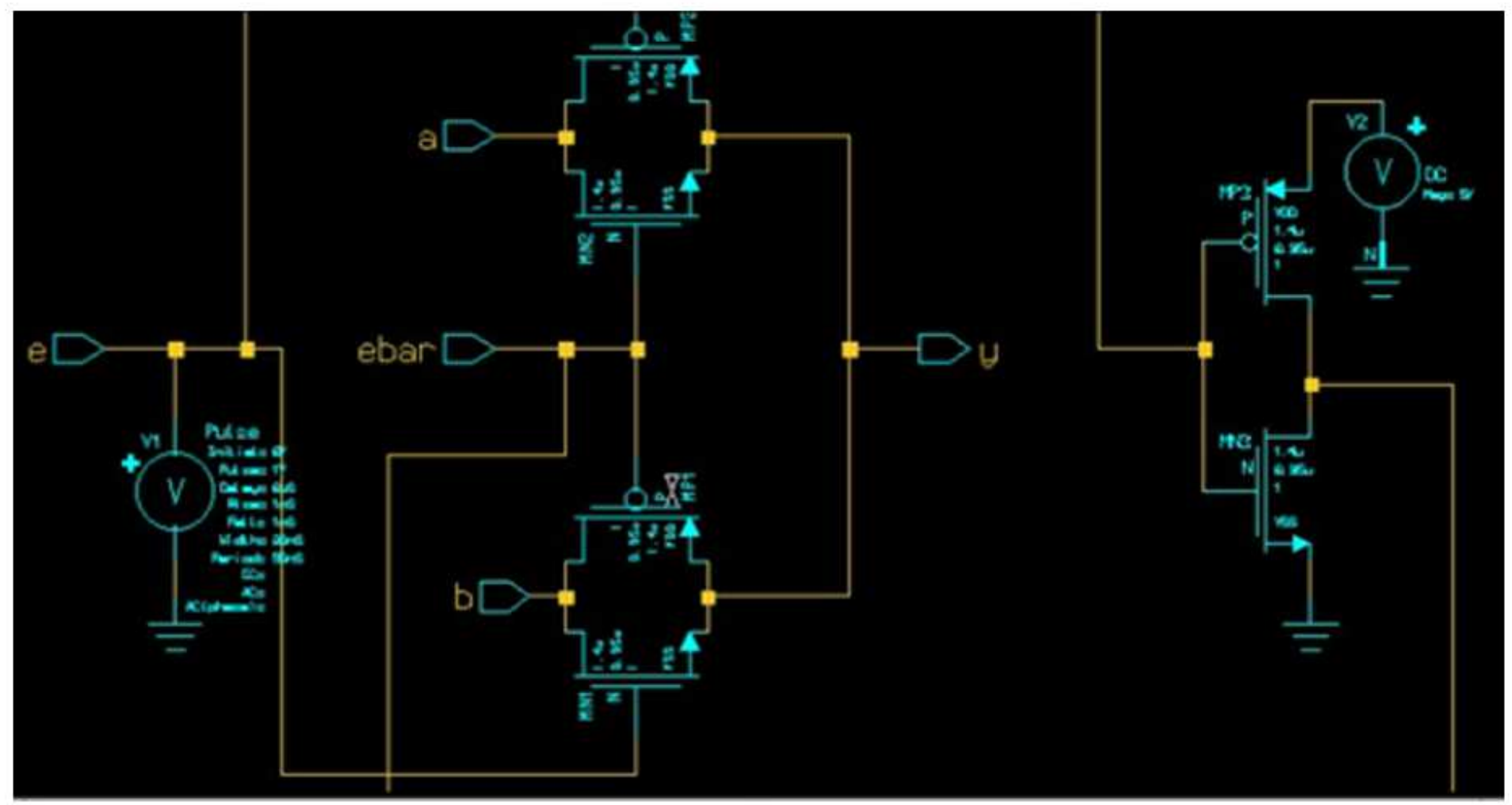

Figure 7

Conventional CMOS based 2:1 Multiplexer

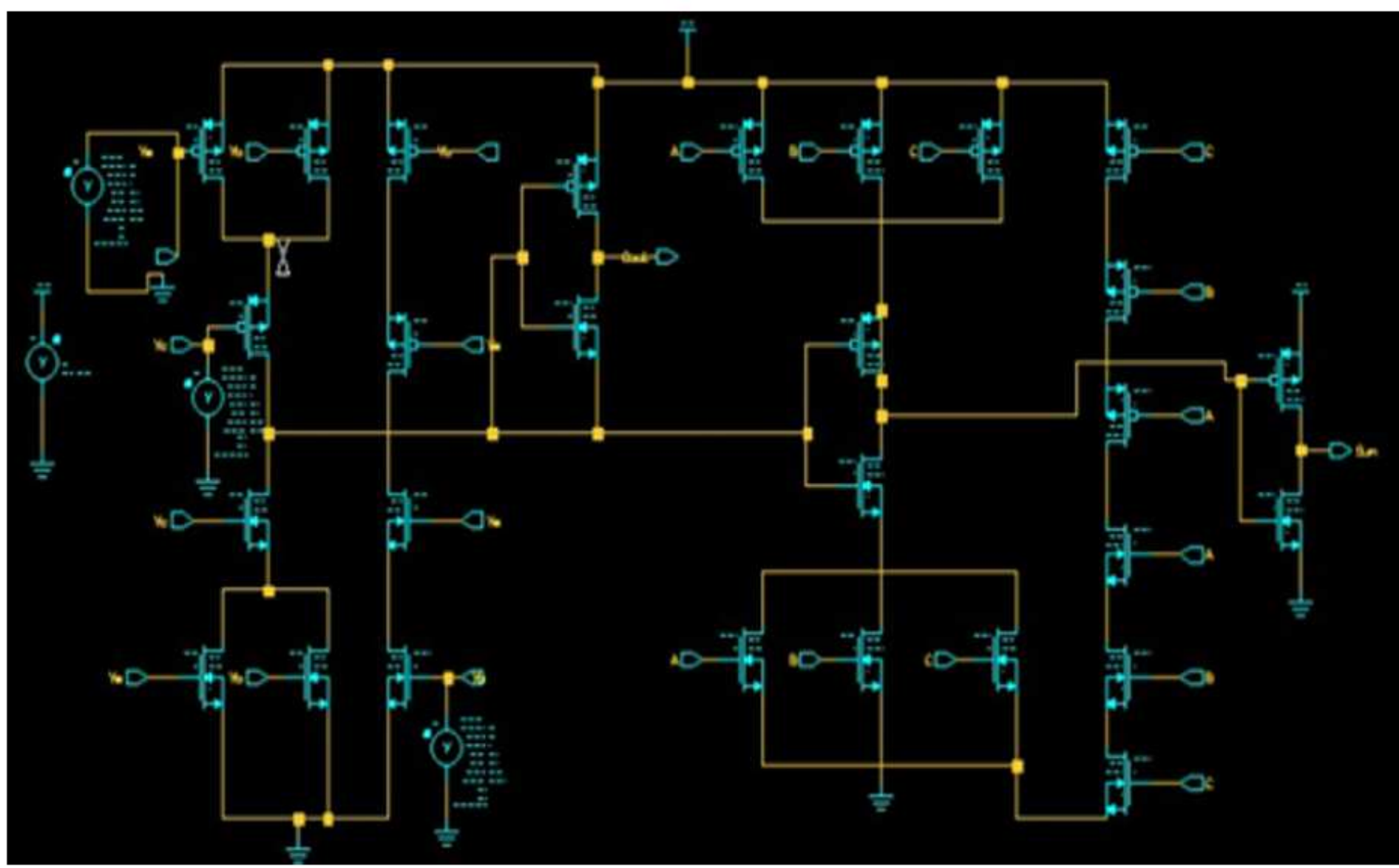


Figure 8

Conventional CMOS based Full Adder

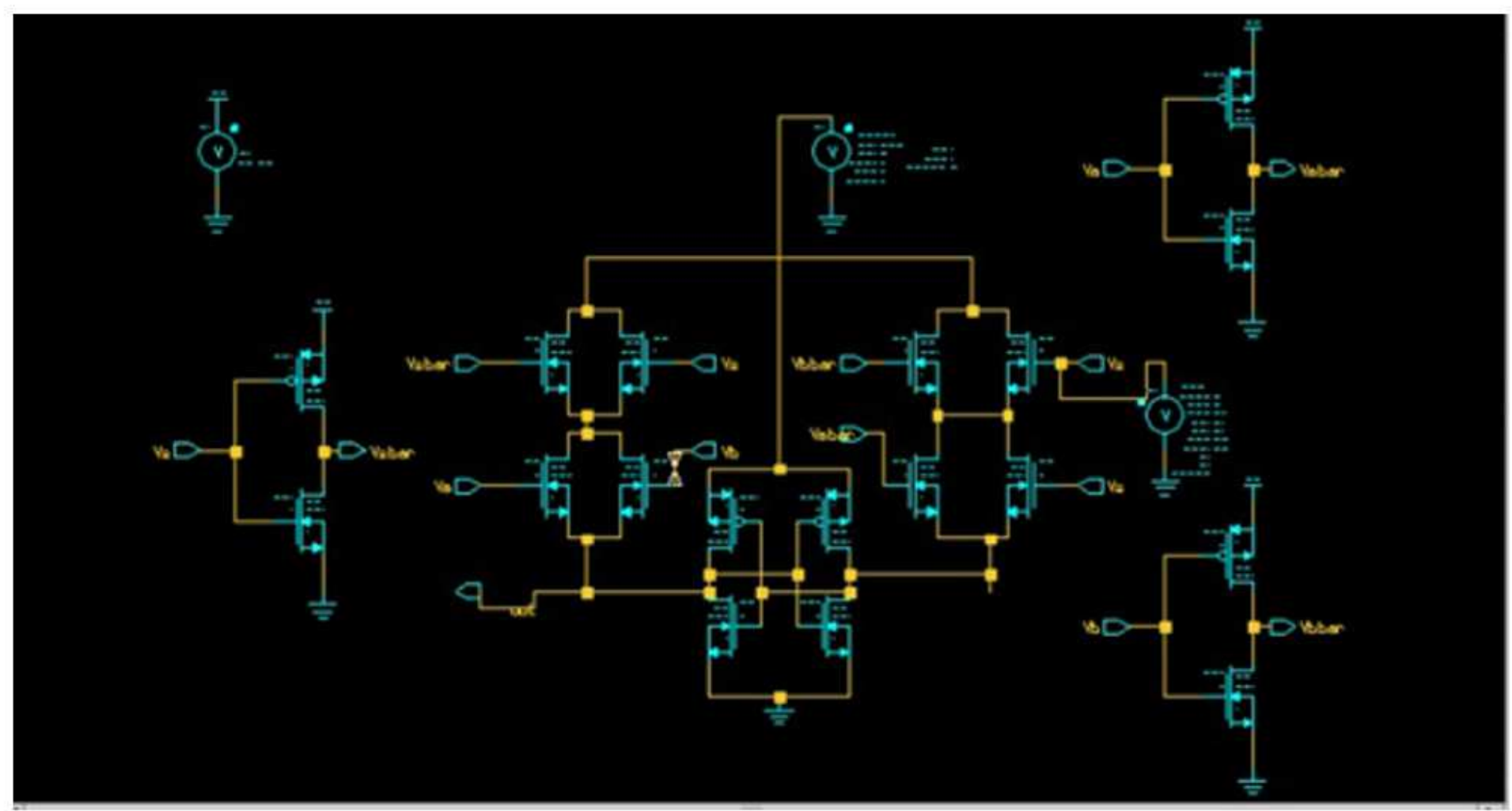

Figure 9

PFAL CMOS 2:1 Multiplexer

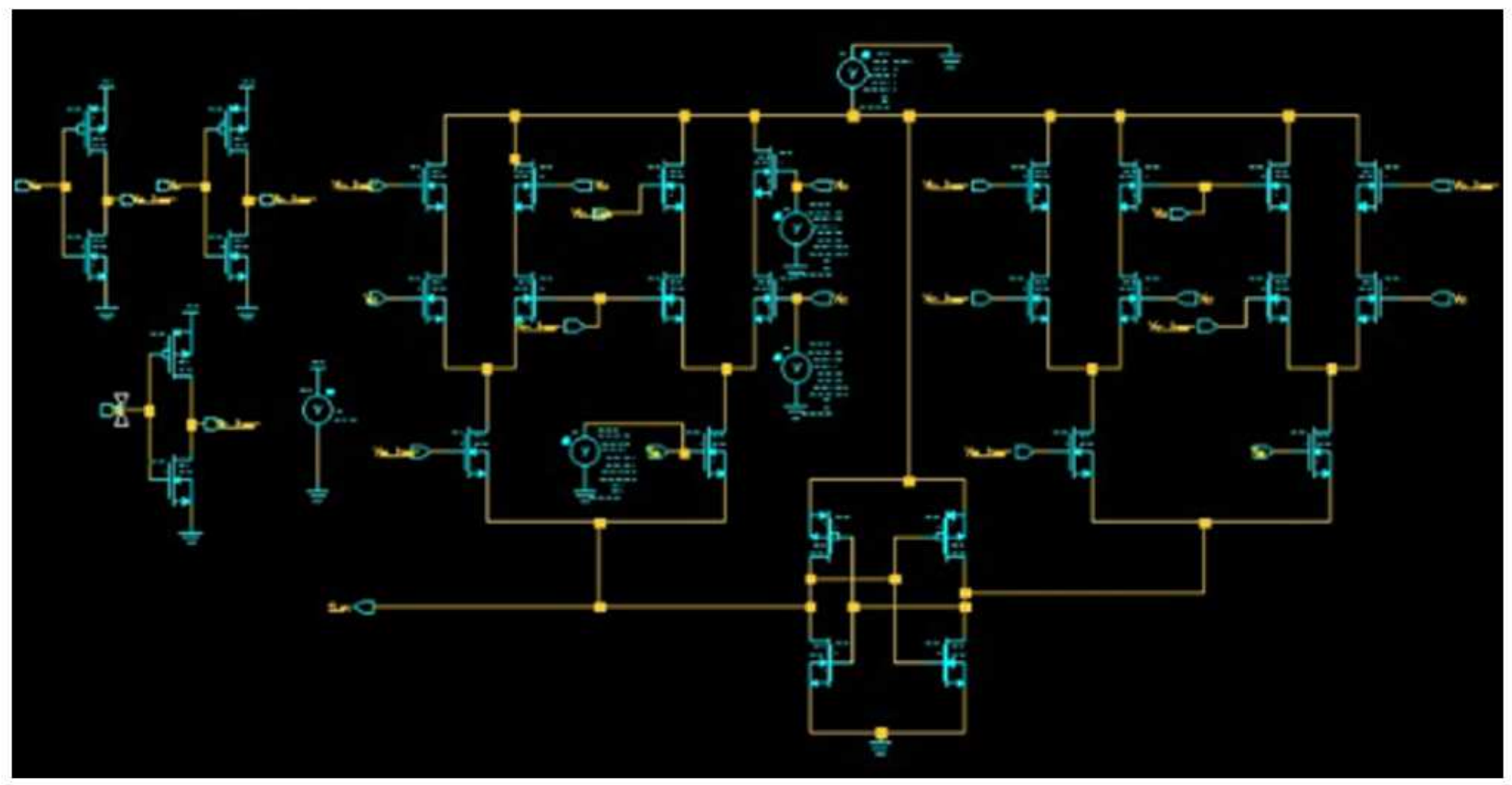


Figure 10

PFAL CMOS based Full Adder

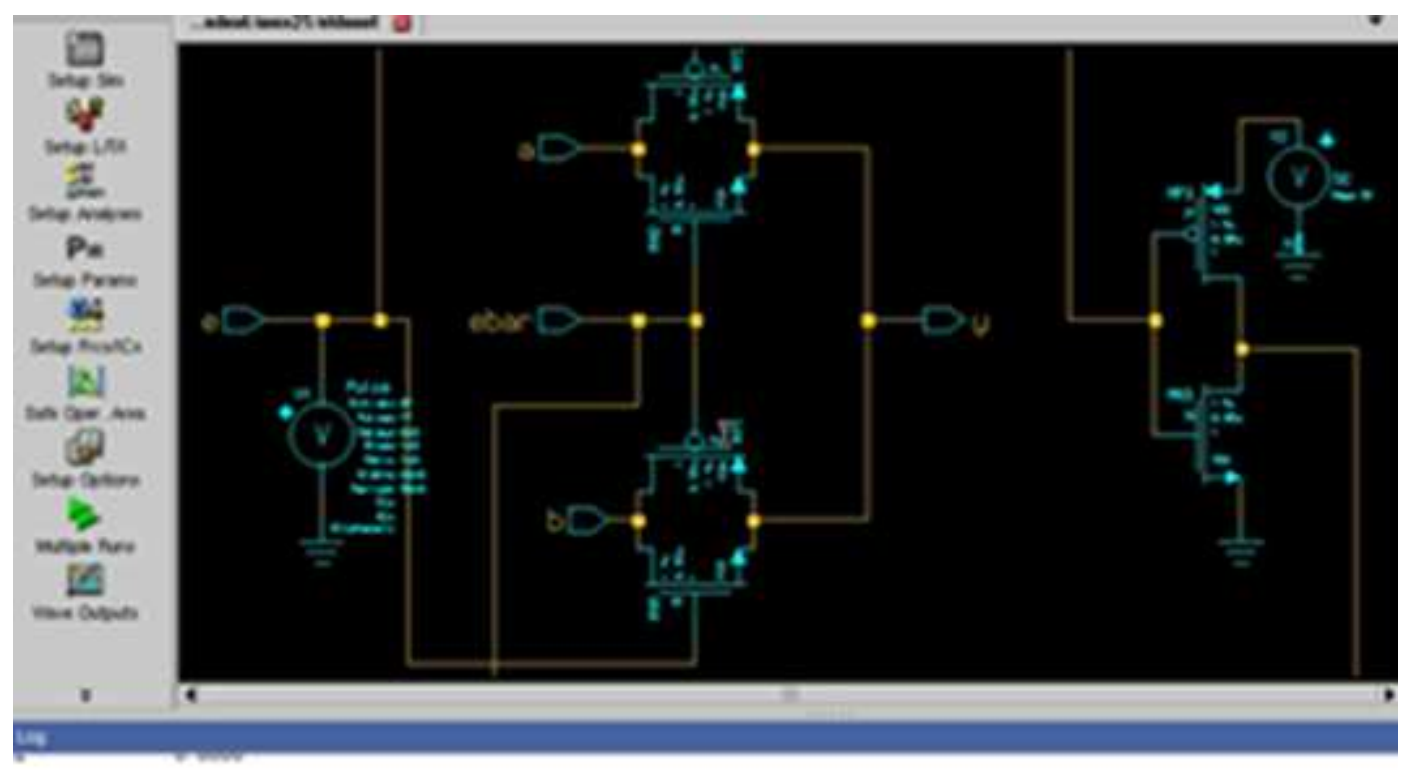

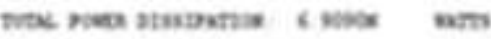

\section{Figure 11}

Calculated power dissipation of Conventional CMOS based 2:1 Multiplexer 109

TUTAL. POVER DISSIPATTON: $6.9090 \mathrm{~N}$ VATTS

Figure 12

Log window of power dissipation of Conventional CMOS based 2:1 Multiplexer 


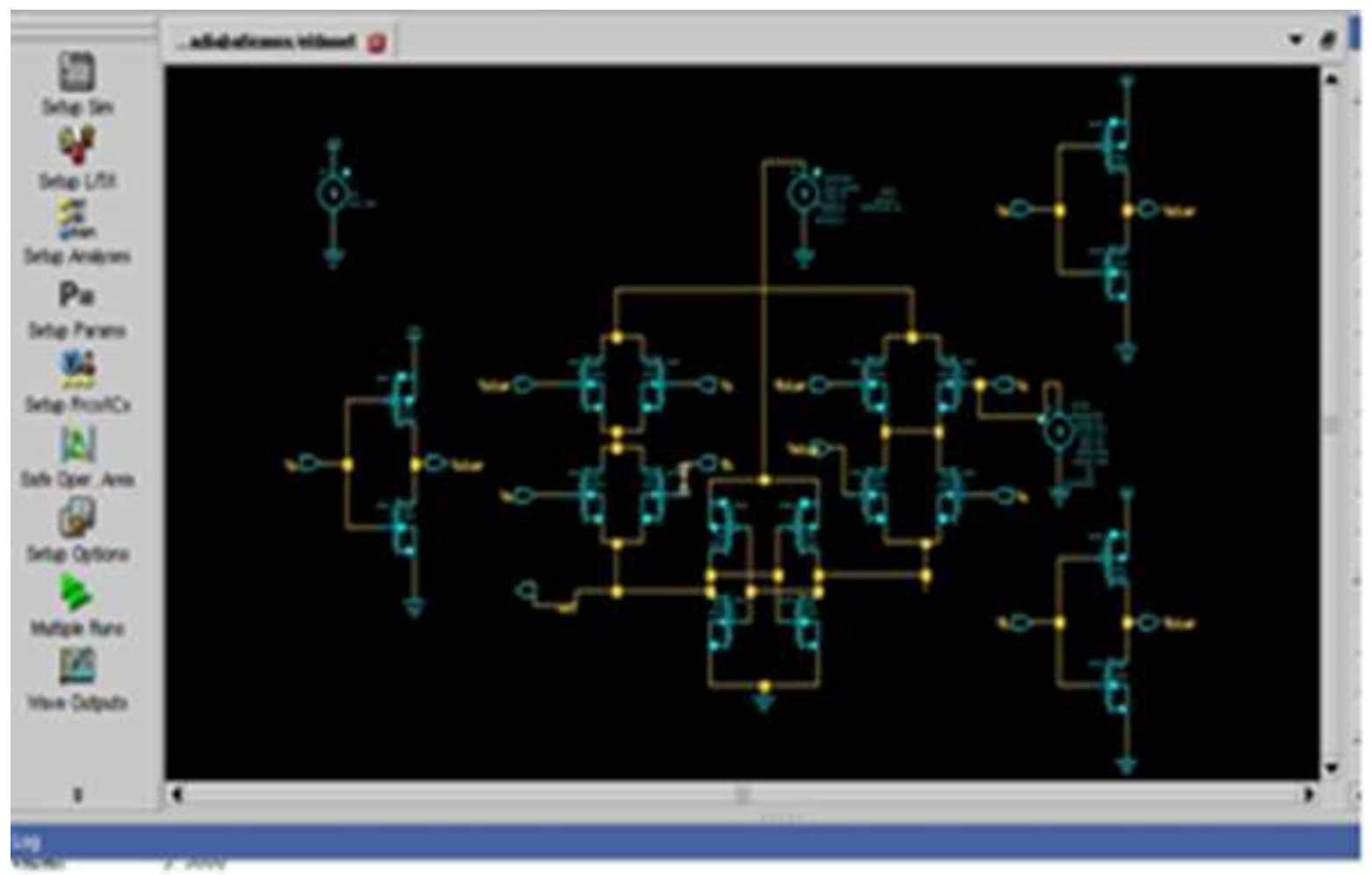

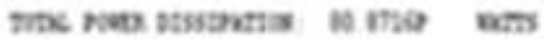

\section{Figure 13}

Calculated power dissipation of PFAL CMOS based 2:1 Multiplexer

tog

nown

TOTAL POVER DISSIPATION: $80.8716 \mathrm{P}$ VATTS

4

Figure 14

Log window of power dissipation for PFAL based 2:1 Multiplexer 


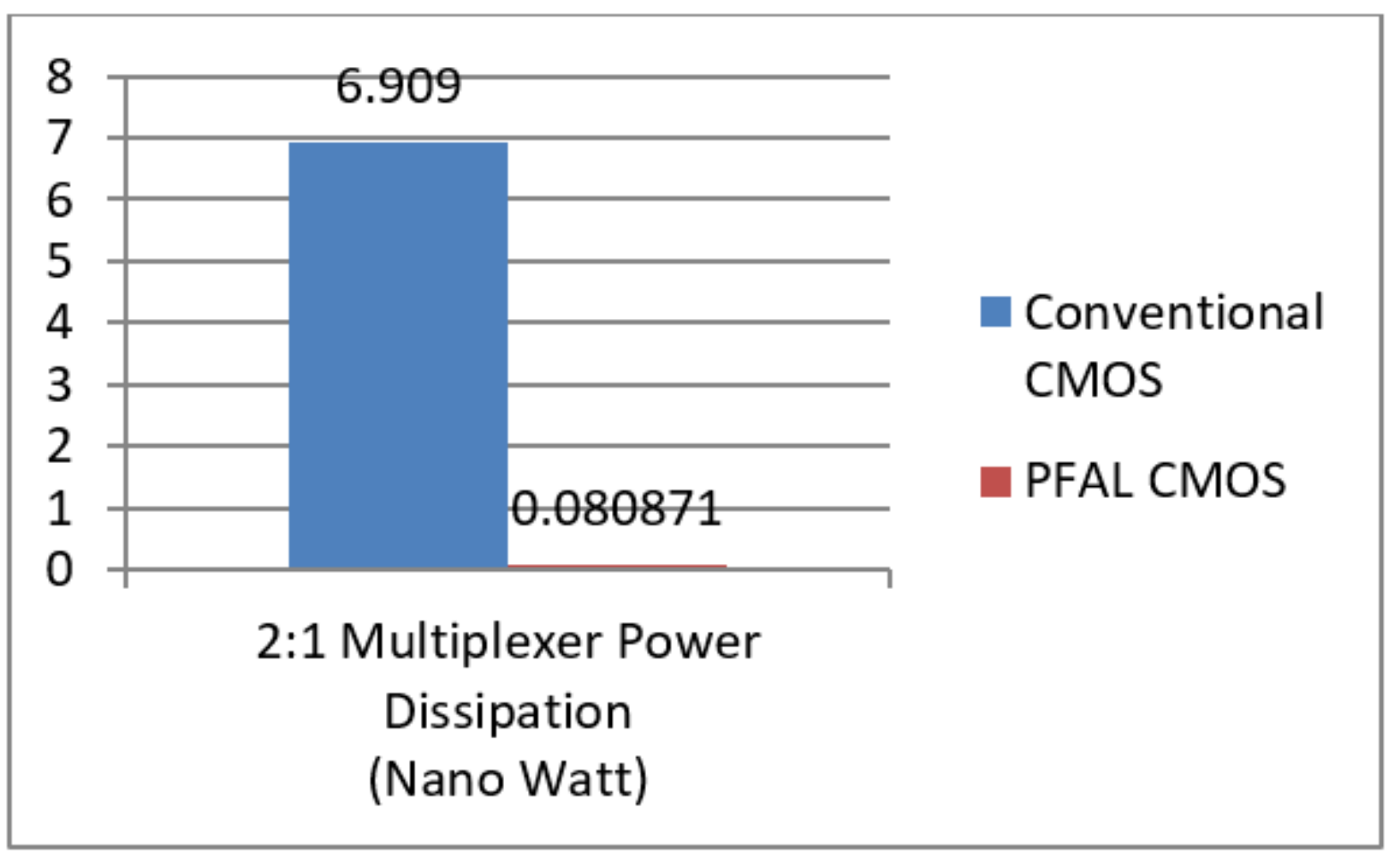

Figure 15

Graphical representation of reduction in power dissipation of 2:1 Multiplexer

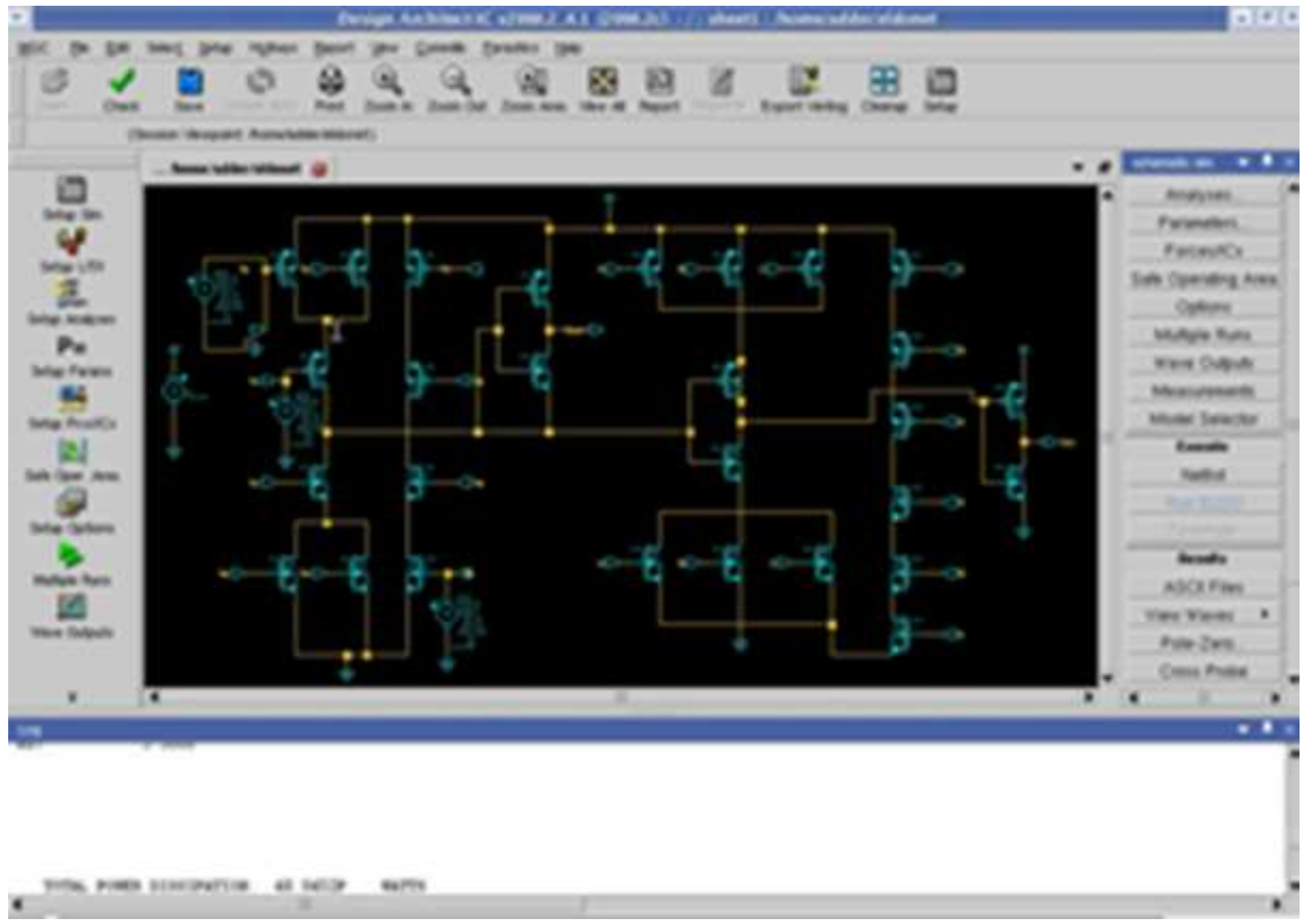

Figure 16 
Calculated power dissipation of conventional CMOS based Full Adder 109

ist

\section{Figure 17}

Log window of power dissipation of conventional CMOS based Full Adder

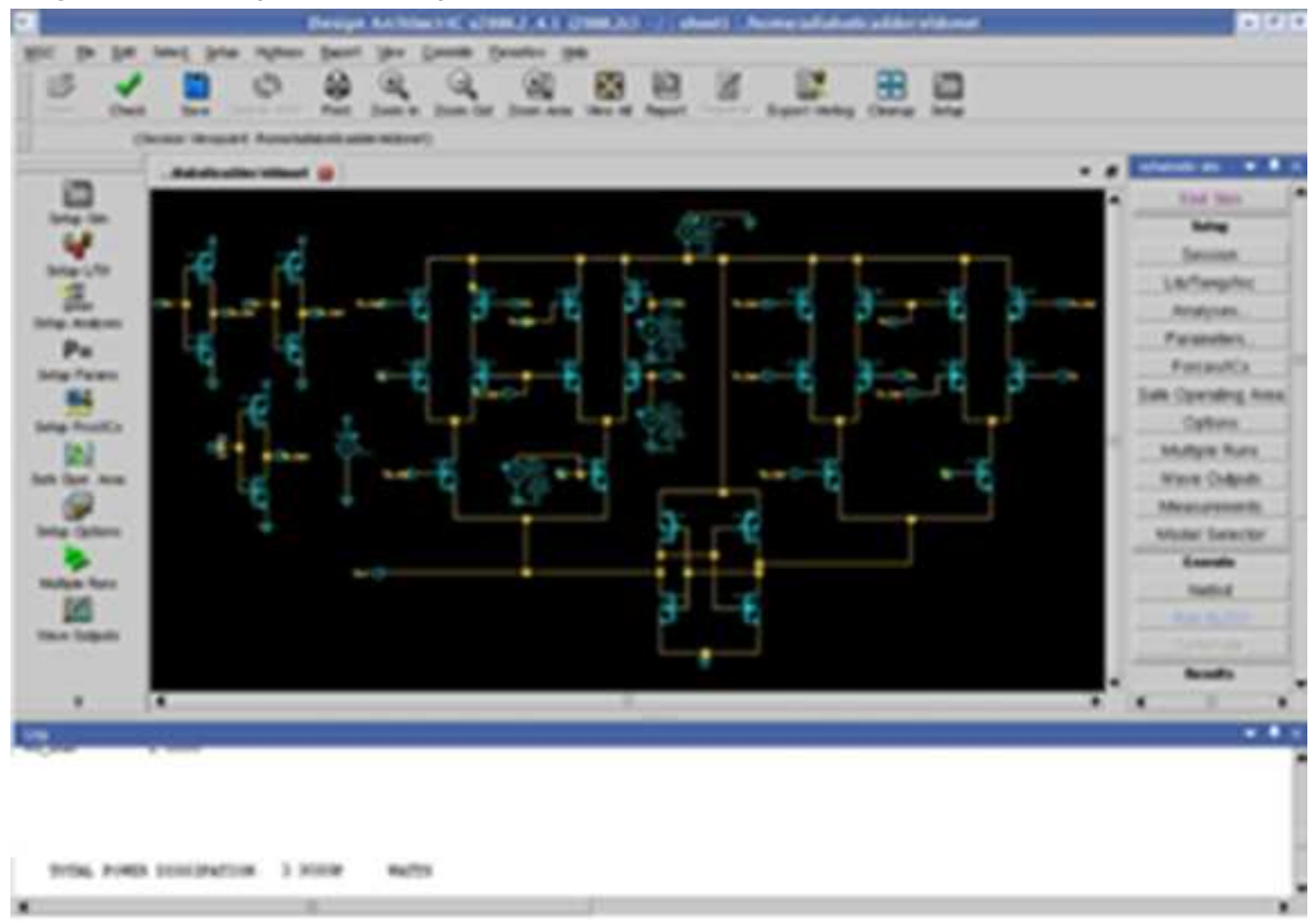

\section{Figure 18}

Calculated power dissipation of PFAL based Full Adder

100

axgav

TOTAL POVRR DISSIPATION: 3.9099P VATS 
Figure 19

Log window of power dissipation for PFAL based Full Adder.

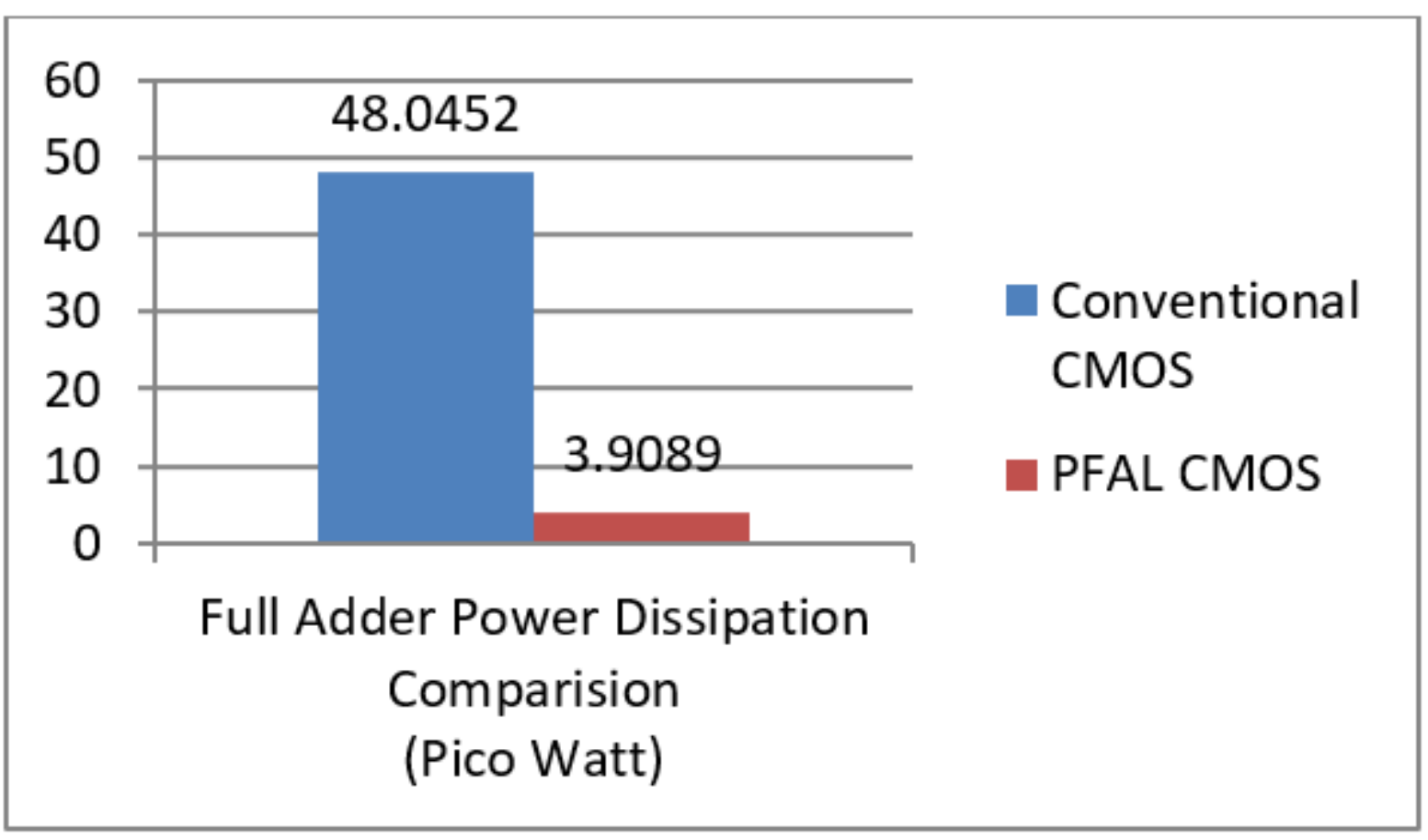

Figure 20

Graphical representation of reduction in power dissipation of Full Adder Circuit 